\title{
SELEÇÃO DE PLANTAS RESISTENTES E DE FUNGICIDAS PARA O CONTROLE DA "MORTE PREMATURA" DO \\ MARACUJAZEIRO, CAUSADA POR Nectria haematococca $\mathbf{E}$
}

Phytophthora parasitica

\author{
IVAN HERMAN FISCHER
}

Dissertação apresentada à Escola Superior de Agricultura "Luiz de Queiroz", Universidade de São Paulo, para obtenção do título de Mestre em Agronomia, Área de Concentração: Fitopatologia.

P I R A C I C A B A

Estado de São Paulo - Brasil

Dezembro - 2003 


\section{SELEÇÃO DE PLANTAS RESISTENTES E DE FUNGICIDAS PARA O CONTROLE DA “MORTE PREMATURA" DO \\ MARACUJAZEIRO, CAUSADA POR Nectria haematococca $\mathbf{E}$}

Phytophthora parasitica

\section{IVAN HERMAN FISCHER \\ Engenheiro Agrônomo}

Orientador: Profa. Dra. LILIAN AMORIM

Dissertação apresentada à Escola Superior de Agricultura "Luiz de Queiroz", Universidade de São Paulo, para obtenção do título de Mestre em Agronomia, Área de Concentração: Fitopatologia.

P I R A C I C A B A

Estado de São Paulo - Brasil

Dezembro - 2003 
Dados Internacionais de Catalogação na Publicação (CIP) DIVISÃO DE BIBLIOTECA E DOCUMENTAÇÃO - ESALQ/ USP

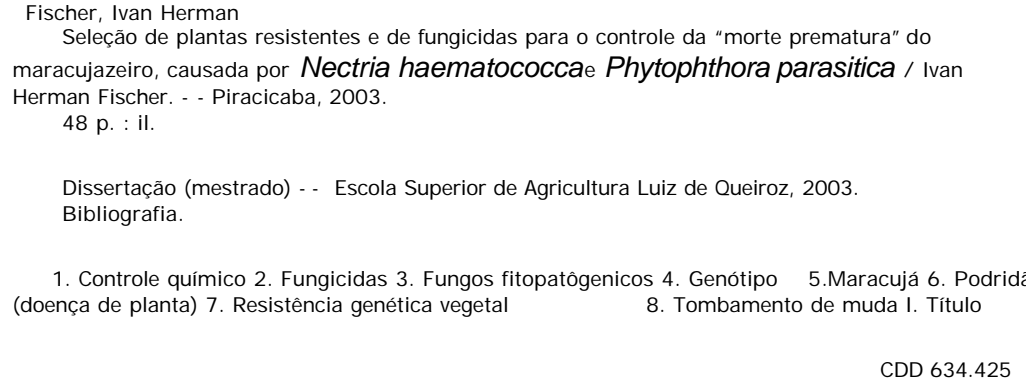

CDD 634.425

\section{"Permitida a cópia total ou parcial deste documento, desde que citada a fonte - $\mathrm{O}$ autor"}


Aos meus queridos pais, Antonio e Mirna (in memorian), meu irmão Heitor e minha companheira Fernanda, pelo apoio, incentivo, compreensão e paciência, com amor, 


\section{AGRADECIMENTOS}

A DEUS pela minha vida, saúde e pelos dons recebidos;

Aos professores Dra. Lilian Amorim e Hiroshi Kimati pelo profissionalismo, pelos valiosos ensinamentos acadêmicos, conselhos, exigências e cobranças dos deveres cumpridos e incentivos na vida profissional. E, sobretudo, pela amizade e lições de vida;

À Escola Superior de Agricultura “Luiz de Queiroz”, especialmente ao Departamento de Entomologia, Fitopatologia e Zoologia Agrícola, pela oportunidade concedida à realização do curso;

À CAPES e à FAPESP pela concessão da bolsa de mestrado, sem a qual não teria condições de desenvolver este projeto;

Aos professores do Setor de Fitopatologia pelos valiosos ensinamentos e cobranças nas disciplinas;

À professora Sônia M. S. Piedade do Departamento de Ciências Exatas pela colaboração na análise estatística dos dados;

Aos funcionários, em especial Marise C. Martins, Silvia Lourenço, Maria H. Duarte de Moraes e Pedro C. Arthuso, pela amizade, paciência e colaboração direta nos trabalhos desenvolvidos;

Aos pesquisadores Laura M. M. Meletti, João C. Oliveira, Maria L. C. Vieira e Maria Rita de Cássia Campos, pelas sementes de maracujazeiro, sem as quais este trabalho não seria possível; 
Aos colegas da Pós-graduação da Fitopatologia: Alexandre F. S. Mello, José S. Giampan, Rock Seille e Silvio A. M. Alves pela amizade, conselhos e colaboração nos trabalhos realizados;

Aos secretários da Pós-Graduação em Fitopatologia, Marina e Jefferson, pela preciosa ajuda com a parte burocrática do curso e pela amizade;

A todos aqueles que direta ou indiretamente contribuíram para a realização deste trabalho. 


\section{SUMÁRIO}

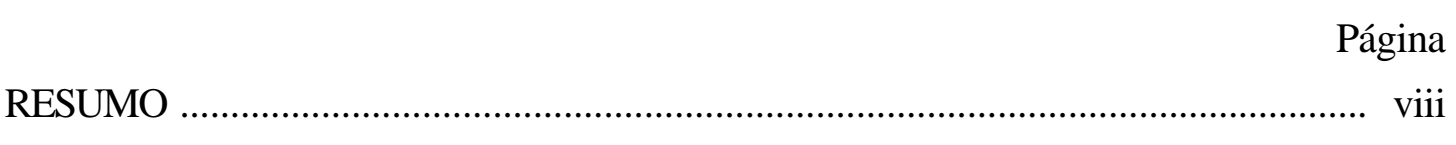

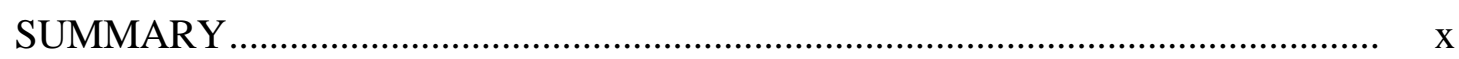

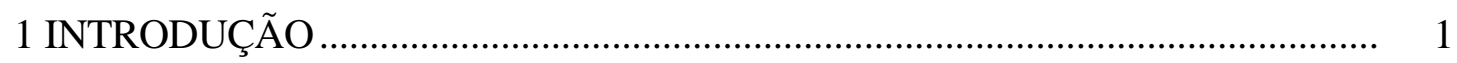

2 REVISÃO DE LITERATURA ...................................................................... 3

2.1 Considerações gerais sobre o maracujazeiro..................................................... 3

2.2 Agentes causais da morte prematura ............................................................... 5

2.3 Controle da morte prematura .......................................................................... 9

3 MATERIAL E MÉTODOS _.................................................................... 12

3.1 Local de execução dos experimentos ............................................................... 12

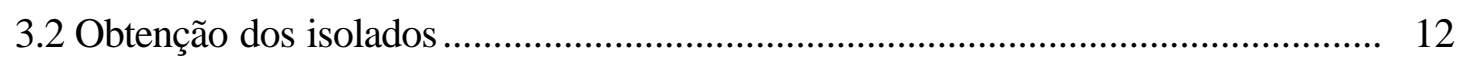

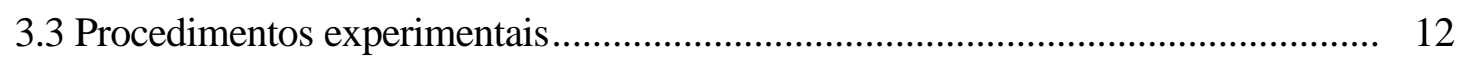

3.3.1 Isolamento e identificação de $N$. haematococca e $P$. parasitica ........................ 12

3.3.2 Teste de patogenicidade .............................................................................. 13

3.3.3 Metodologia de inoculação e idade das plantas ............................................... 15

3.3.4 Avaliação da ocorrência de damping-off e podridão de colo .............................. 16

3.3.5 Comportamento de genótipos de maracujazeiro a $N$. haematococca e $P$.

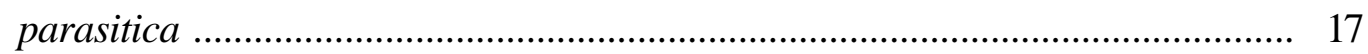

3.3.6 Inibição in vitro do crescimento micelial de $N$. haematococca e $P$. parasitica ... 17

3.3.7 Tratamento químico erradicante em solo infestado .......................................... 19

3.3.8 Tratamento químico curativo ................................................................. 20 


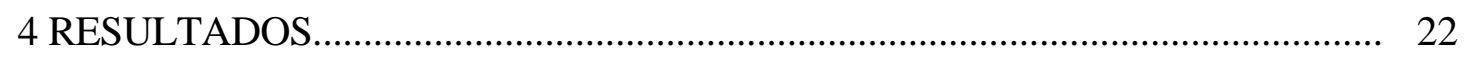

4.1 Metodologia de inoculação e idade das plantas ................................................... 22

4.2 Damping-off e podridão de colo de P. edulis f. flavicarpa .................................. 24

4.3 Comportamento de Passifloraceas .................................................................... 25

4.4 Comportamento de genótipos de P. edulis f. flavicarpa ........................................ 28

4.5 Inibição in vitro do crescimento micelial de $N$. haematococca ............................. 29

4.6 Inibição in vitro do crescimento micelial de $P$. parasitica ................................... 31

4.7 Tratamento químico erradicante em solo infestado ............................................ 34

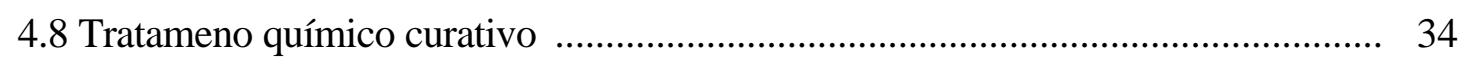

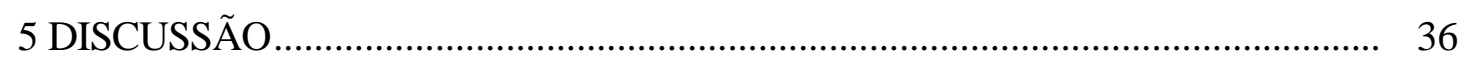

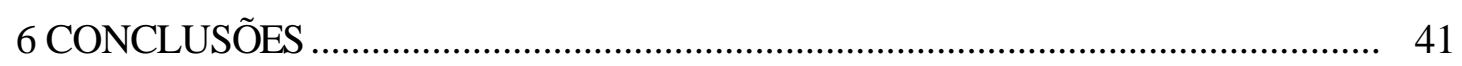

REFERÊNCIAS BIBLIOGRÁFICAS .............................................................. 42 


\section{SELEÇÃO DE PLANTAS RESISTENTES E DE FUNGICIDAS PARA O CONTROLE DA "MORTE PREMATURA" DO MARACUJAZEIRO, CAUSADA POR Nectria haematococca $\mathbf{E}$ Phytophthora parasitica}

Autor: IVAN HERMAN FISCHER

Orientador: Profa. Dra. LILIAN AMORIM

\section{RESUMO}

O presente trabalho teve por objetivos avaliar métodos de inoculação de Nectria haematococca e Phytophthora parasitica e idades de Passiflora edulis f. flavicarpa suscetíveis à infecção; avaliar a ocorrência de damping-off e podridão de colo do maracujazeiro em solo infestado; avaliar o comportamento de diferentes Passsifloraceas e genótipos de maracujazeiro amarelo aos respectivos patógenos; realizar testes de controle químico in vitro, tratamento químico erradicante em solo infestado e tratamento químico curativo em $P$. edulis f. flavicarpa para os respectivos patógenos. Inoculações no colo das plantas de P. edulis f. flavicarpa proporcionaram maiores níveis de doença comparadas às inoculações no sistema radicular, previamente ferido. Os resultados sugerem que $N$. haematococca seja um patógeno que penetra através de ferimentos. A mortalidade foi maior quando a inoculação foi realizada em plantas mais jovens e quando os patógenos $N$. haematococca e $P$. parasitica estavam em associação. Dentre as 
17 espécies de Passiflora avaliadas para resistência aos patógenos, as espécies $P$. nitida, $P$. laurifolia e $P$. alata apresentaram as menores médias de lesões de $N$. haematococca, enquanto que para $P$. parasitica foram as espécies $P$. suberosa, $P$. foetida e $P$. morifolia as menos afetadas. Passiflora sidaefolia, P. edulis f. flavicarpa e P. edulis f. edulis foram as mais suscetíveis a ambos os patógenos, com sintomas que culminaram com a morte de plantas. Os genótipos de $P$. edulis f. flavicarpa mais resistentes a $N$. haematococca foram os procedentes de Morretes (PR) e a variedade Maguari e de Sapucaí (SP), enquanto que para $P$. parasitica foram os genótipos de Morretes (PR), Jaboticabal (SP) e LE13P2 (IAC) os menos afetados. A variedade Sul-Brasil e o genótipo de Livramento (BA) foram altamente suscetíveis a ambos os patógenos, com sintomas que culminaram com a morte de plantas. No teste de fungitoxidade in vitro avaliou-se a eficiência dos fungicidas na inibição do crescimento micelial de $N$. haematococca e $P$. parasitica. Na dose $100 \mathrm{ppm}$ somente prochloraz inibiu totalmente o crescimento micelial de $N$. haematococca e nenhum produto inibiu acima de $82 \%$ o crescimento de $P$. parasitica. Os fungicidas prochloraz, thiabendazole, thiram+thiabendazole, carbendazim, triflumizole e captan exerceram controle erradicante em solo infestado com $N$. haematococca, inibindo a incidência da doença em plantas com seis semanas pós-germinação. O mesmo foi observado com os produtos kif, dimethomorph, metalaxyl+mancozeb, mancozeb, cymoxanil+maneb e oxicloreto de cobre para $P$. parasitica. Os fungicidas testados em tratamento curativo inibiram o desenvolvimento da doença com melhores resultados quando aplicados dois dias após a inoculação, comparado a sete dias. Os fungicidas prochloraz e carbendazim destacaramse por evitar a morte de plantas inoculadas com $N$. haematococca e os fungicidas kif, dimethomorph, metalaxyl+mancozeb e cymoxanil+maneb apresentaram eficiência semelhante entre si e superior a fosetyl- $\mathrm{Al}$ no controle de $P$. parasitica. 


\section{SELECTION OF RESISTANT PLANTS AND FUNGICIDES FOR THE CONTROL OF PASSION FRUIT "PREMATURE DEATH", CAUSED BY Nectria haematococca AND Phytophthora parasitica}

Author: IVAN HERMAN FISCHER

Adviser: Prof. Dra. LILIAN AMORIM

\section{SUMMARY}

The objectives of the present work were to evaluate methods of inoculation of Nectria haematococca and Phytophthora parasitica and ages of Passiflora edulis f. flavicarpa which are susceptible to infection; to evaluate the damping-off and collar rot of passion fruit plant in infested soil; to evaluate the behavior of different Passsifloraceas and yellow genotypes of passion fruit to the respective pathogens; to carry out tests of chemical control in vitro, eradicative chemical treatment in infested soil and curative chemical treatment in $P$. edulis f. flavicarpa for the respective pathogens. Inoculations in the collar zone of $P$. edulis f. flavicarpa plants provided higher levels of disease when compared to the inoculations in the radicular system previously wounded. The results suggest that $N$. haematococca is a pathogen that penetrates through wounds. Mortality was higher when the inoculation was carried out in younger plants and when both pathogens were together. Amongst the 17 species of Passiflora tested for resistance to the pathogens, P. nitida, P. laurifolia, and P. alata 
showed the lowest average of $N$. haematococca lesions, while $P$. suberosa, $P$. morifolia, and $P$. foetida were the least affected species by $P$. parasitica. Passiflora sidaefolia, $P$. edulis f.flavicarpa, and P.edulis f. edulis were the most susceptible to both pathogens, showing symptoms that culminated with the death of the plants. The most resistant genotypes of P. edulis f. flavicarpa to $N$. haematococca were those from Morretes (PR), Maguari variety, and those from Sapucaí (SP); with respect to P. parasitica, the genotypes from Morretes (PR), Jaboticabal (SP), and LE13P2 (IAC) were the least affected. The Sul-Brasil variety and the genotype from Livramento (BA) had been highly susceptible to both pathogens, having symptoms that culminated with the death of plants. The in vitro efficiency of the fungicides in the inhibition of the mycelial growth of N. haematococca and P. parasitica was evaluated. At 100 ppm, only prochloraz inhibited totally the mycelial growth of $N$. haematococca and no product inhibited over $82 \%$ the growth of $P$. parasitica. Prochloraz, thiabendazole, thiram+thiabendazole, carbendazim, triflumizole, and captan controlled eradicatively the soil infested by $N$. haematococca, inhibiting the incidence of the disease in plants which were six weeks old. The same was observed for the products kif, dimethomorph, metalaxyl+mancozeb, mancozeb, cymoxanil+maneb, and copper oxychloride for $P$. parasitica. The tested fungicides in curative treatment inhibited the development of the disease with better results when applied two days after the inoculation, compared to seven days. Prochloraz and carbendazim were outstanding for preventing the death of plants inoculated with $N$. haematococca. Kif, dimethomorph, metalaxyl+mancozeb, and cymoxanil+maneb showed similar efficiency and were superior to fosetyl $\mathrm{Al}$ in the control of $P$. parasitica. 


\section{INTRODUÇÃO}

O Brasil, centro de origem de um grande número de espécies da família Passifloraceae, destaca-se como o principal produtor mundial do maracujá-amarelo (Passiflora edulis f. flavicarpa Deg.), seguido da Colômbia, do Peru e do Equador, produzindo também o maracujá-doce (Passiflora alata Dryand.) e o maracujá-roxo (Passiflora edulis f. edulis Sims.), em menor escala. Um dos fatores da baixa produtividade do maracujazeiro, principalmente no Nordeste, maior região produtora, é o manejo inadequado de doenças em pré e pós-colheita, notadamente da "morte prematura". Nesse agroecossistema, as plantas de maracujá vêm morrendo antes de completar dois anos de idade, precocemente, ao considerar-se que o período normal de vida útil dessa cultura deveria ser de três a quatro anos. Em Araguari (MG), onde existem aproximadamente 2600 hectares de maracujazeiro, os plantios são renovados anualmente (EMBRAPA Cerrados). Além do curto período de vida útil da cultura, ocorre redução considerável na produtividade e qualidade dos frutos. Esse processo inicia-se com o amarelecimento e secamento de ramos, queda acentuada de frutos imaturos, até o secamento de toda a planta, resultado da podridão do colo e do sistema radicular. Esses mesmos sintomas podem ser observados também em plantas de maracujá-doce, embora esta espécie seja considerada pela grande maioria dos autores como resistente.

Com relação à etiologia da morte prematura, Nectria haematococca Berk \& $\mathrm{Br}$. é considerado o principal agente causal da doença. Atualmente a doença encontra-se relatada em vários países onde se cultiva o maracujazeiro, como EUA (Ploetz, 1991), China (Li et al, 1993), Venezuela (Cedeño et al., 1990) e África do Sul (Cole et al., 1992). De acordo com Ponte et al. (1998), este fungo está disperso por todos os Estados brasileiros produtores, sendo responsável, em muitos casos, por constantes migrações da 
cultura. O patógeno Phytophthora spp. também pode estar associado aos sintomas da doença, como relatado por Ponte (1993) em vários Estados do Nordeste; podendo ainda atuar concomitantemente a $N$. haematococca (Cole et al., 1992; Fischer et al., 2003a). No município de Jaboticabal (SP) a morte prematura ocorre com frequiência, porém ainda não se conseguiu confirmar a etiologia da doença. Em replantio de maracujazeiro efetuado em áreas com histórico de ocorrência da doença observam-se sintomas após três meses, suportando a hipótese da causa da doença estar mesmo no solo. Os patógenos penetram por ferimentos nas raízes e colo da planta e são favorecidos pelo encharcamento do solo.

Como principais medidas de controle da morte prematura do maracujazeiro recomenda-se favorecer a boa drenagem do terreno, corrigir o $\mathrm{pH}$ do solo e manter a integridade do sistema radicular, erradicando as plantas doentes (Ruggiero et al., 1996).

O presente trabalho teve por objetivos avaliar métodos de inoculação de Nectria haematococca e Phytophthora parasitica e idades de Passiflora edulis f. flavicarpa suscetíveis à infecção; avaliar a ocorrência de damping-off e podridão de colo do maracujazeiro em solo infestado; avaliar o comportamento de diferentes Passsifloraceas e genótipos de maracujazeiro amarelo aos respectivos patógenos; realizar testes de controle químico in vitro, tratamento químico erradicante em solo infestado e tratamento químico curativo em P. edulis f. flavicarpa para os respectivos patógenos. 


\section{REVISÃO DE LITERATURA}

\subsection{Considerações gerais sobre o maracujazeiro}

O Brasil é o maior produtor mundial de maracujá-amarelo (Passiflora edulis $\mathrm{f}$. flavicarpa) com uma produção aproximada de 330.777 toneladas (FNP Consultoria \& Agroinformativos, 2003). Os mercados de suco e de fruta fresca têm crescido, e a produção, embora estagnada nos últimos anos, é substancialmente maior que aquela de décadas anteriores (Aguiar \& Santos, 2001). O destino da produção varia de acordo com a região, porém verifica-se ao longo das últimas duas décadas uma inversão: o mercado da fruta fresca que absorvia, aproximadamente, $30 \%$ da produção nacional hoje absorve mais da metade (Ruggiero \& Oliveira, 1998). O suco da fruta concentrado ocupa o segundo lugar na pauta de exportações brasileiras de sucos de frutas que movimenta um mercado mundial de 5,0 bilhões de dólares/ano (Ruggiero et al., 1996). O mercado internacional de maracujá é considerado emergente, necessitando apenas de uma garantia de continuidade de fornecimento ao longo dos anos. A cultura está presente em praticamente todas as regiões do país e os principais Estados produtores são Bahia $(23,40 \%)$, São Paulo (17,50 \%), Sergipe (10,83\%), Minas Gerais (7,62 \% e Goiás (7,14\%) (FNP Consultoria \& Agroinformativos, 2003).

A produtividade dos poma res brasileiros de maracujá é bastante variável, estando a média nacional em torno de 10 a 12 tha/ano, embora existam pomares com produção acima de 40 t/ha/ano em plantações de vida útil de dois anos, sendo baixa quando comparada à de outros países produtores, como por exemplo, o Havaí com 45 t/ha/ano (Ruggiero et al., 1996; Oliveira \& Ruggiero, 1998).

O maracujazeiro é uma planta tropical, com ampla variabilidade genética. Segundo Vanderplank (1996), a família Passifloraceae é formada por 18 gêneros e 630 
espécies, sendo o gênero Passiflora o mais importante economicamente, composto de 24 subgêneros e 465 espécies. Dentre as muitas espécies de Passiflora mundialmente cultivadas por terem seus frutos comestíveis, destacam-se P. edulis f. edulis, P. edulis f. flavicarpa, P. liguraris Juss., P. molissima (HBK.) Bailey, P. quadrangularis L., P. alata (Martin \& Nakasone, 1970; Oliveira, 1987). Passiflora suberosa, P. speciosa, P. ovata e $P$. bahiensis são cultivadas para doces e compotas. Algumas espécies de Passiflora como $P$. caerulea, $P$. elegans, $P$. raddiana e $P$. picturata são cultivadas por suas propriedades ornamentais e outras são cultivadas como plantas que encerram propriedades medicinais, como $P$. foetida, P. laurifolia, P. edulis, P. vellozzi, $P$. capsularis, P. sicyoides, P. quadrangularis, P. bahiensis, P. incarnata, P. mucronata, $P$. quadriglandulosa, P. perfoliata e P. alata (Oliveira, 1987; Freitas, 1987). Outras espécies exploradas no Brasil, de menor importância comercial e cultivo bastante regionalizado são $P$. cincinnata e $P$. nitida (Inglez de Souza \& Meletti, 1997; Piza Junior, 1998; Pereira et al., 1998).

A partir dos anos 70, o cultivo do maracujá-amarelo difundiu-se largamente por todo o Brasil, em razão da instalação de unidades processadoras de frutos para suco, dos bons preços pagos pelas industrias aos produtores, diante de um aumento na demanda do mercado internacional e interno de sucos e da fruta in natura (Cacex, 1987). A expansão da área plantada, entretanto, fez-se acompanhar do surgimento e agravamento de um grande número de doenças, incluindo as do sistema radicular, importantes devido aos prejuízos que causam, provocando mudanças periódicas do local de plantio. Estas doenças podem ser causadas por Fusarium solani (Mart.) Sacc. (F. teleomórfica: Nectria haematococca Berk \& Br.), Thielaviopsis basicola (Berk \& Broome) Ferraris, Sclerotinia sclerotiorum (Lib.) de Bary, Fusarium sambucinum Fuckel (Masuda, 1974; Nakamura, 1980), Fusarium pallidoroseum (Cooke) Saccardo (Delanoë, 1991), Fusarium spp. e Phytophthora spp. Dentre as de maior importância destacam-se a morte prematura ou podridão do colo causada por N. haematococca e Phytophthora spp., e aquelas da parte aérea, como a bacteriose (Xanthomonas axonopodis pv. passiflorae), antracnose (Colletotrichum gloeosporioides Penz) e verrugose (Cladosporium 
herbarium Kink) e também algumas viroses, com destaque para o vírus do endurecimento do fruto (PWV) (Ruggiero et al., 1996).

\subsection{Agentes causais da morte prematura}

Nakamura (1980) e Oliveira \& Ruggiero (1998) relataram que no Estado de São Paulo ocorre um grave problema na cultura do maracujazeiro, geralmente em plantas adultas, resultando em murcha e morte da plantas. Este problema tem sido responsável pelo insucesso dessa cultura em algumas regiões do Estado e está associada à desintegração dos tecidos corticais do colo da planta e das raízes logo após a ocorrência de períodos de chuvas intensas. As tentativas de identificação do agente causal da doença não foram bem sucedidas.

A murcha de Fusarium causada por F. oxysporum (Schlecht.) emend. Snyd. \& Hans. f. sp. passiflorae (Purss, 1954) apresentou ampla disseminação na Austrália, a partir da década de 50, causando a murcha dos plantios comerciais de maracujá-roxo (Mcknight, 1951). Em 1968, foi constatada em São Paulo em plantas da cultivar amarelo-rosado ( $P$. edulis Sims). Cortes longitudinais no lenho do tronco ou ramos grossos revelam manchas ferruginosas típicas do ataque de $F$. oxysporum f. sp. passiflorae, coloração esta devido à ação de fenoloxidase produzida pelo patógeno e transportada pela seiva. Num estado avançado da doença, o colo e as raízes das plantas atacadas apresentam-se em processo de decomposição devido a infecções secundárias (Yamashiro et al., 1973). O controle pode ser obtido pela utilização de porta-enxertos resistentes, como o maracujá-amarelo, ou pelo uso de híbridos resistentes oriundos do cruzamento do maracujá-roxo com o maracujá-amarelo (Gardner, 1989).

Os sintomas ocasionados por $N$. haematococca são semelhantes aos descritos para F. oxysporum f. sp. passiflorae, diferindo por não ter ação sistêmica na planta. Os sintomas são cancros arroxeados localizados nos tecidos do colo e das raízes das plantas, iniciando-se com rachaduras e intumescimento da casca, formando extensas áreas em decomposição com aspecto corticoso, expondo os tecidos do câmbio, refletindo em sintomas na copa através de um ligeiro amarelecimento e perda da turgescência dos brotos terminais, seguida de uma murcha brusca e queda das folhas. 
Vários microrganismos foram isolados a partir de amostras do colo e raízes de maracujazeiros doentes, mas somente $N$. haematococca estava freqüentemente associado à doença (Oliveira et al., 1988; Lutchmeah \& Musaphur, 1993; Ploetz, 1991). Plantas de maracujá de três ou seis meses de idade inoculadas com uma suspensão de conídios na região do colo previamente ferido, com um pequeno corte, comprovaram a patogenicidade destes isolados. O fungo $N$. haematococca apresenta, em meio de cultura, colônias de cor branca-acinzentadas, com áreas de cor verde-limão, que são locais de maior concentração de conídios de $F$. solani, fase anamórfica de $N$. haematococca. Os microconídios medem 8-16 x 2-4 micrômetros, são cilíndricos e alguns podem apresentar um septo, sendo produzidos em grande quantidade, nas extremidades de microconidióforos. Já os macroconídios medem 35-55 x 5-6 micrômetros, com cinco a nove septos, formato fusiforme e originam-se de conidióforos emergentes de esporodóquios. Os clamidósporos são globosos, de parede ligeiramente enrugada, formados isoladamente ou em pares e correspondem às estruturas de resistência de N. haematococca (Booth, 1977). A produção de peritécios de coloração avermelhada se inicia após cerca de sete semanas do plaqueamento do fungo em meio de cultura e dentro de sete a dez dias em lesões de tecido doente sob alta umidade (Emechebe \& Mukiibi, 1976). F. solani é um fungo polífago, afetando um grande número de gêneros de plantas cultivadas, destacando-se fumo, feijão, batatinha, beterraba e pimentão (Viennot-Borgin, 1949); entretanto, estudos em Taiwan demonstraram que $N$. haematococca do maracujazeiro é uma forma especializada ao gênero Passifora (Lin \& Chang, 1985).

Duas espécies de Phytophthora foram identificadas como agentes điológicos da podridão do pé ou podridão do colo: P. cinnamomi Rands. na Austrália e Nova Zelândia (Simmonds, 1959; Young, 1970) e P. nicotianae var. parasitica (sin.: P. parasitica J. F. Dastur) no Zimbábue, na África do Sul, na Malásia, em Taiwan, na Austrália, na Venezuela e no Brasil (Simmonds, 1959; Van den Boom \& Huller, 1970; Kueh \& Voon, 1985; Lin \& Chang, 1985; Grech \& Rijkenberg, 1991; Cole et al., 1992; Gonzalez et al., 2000; Fischer et al., 2003a). Os sintomas ocasionados por Phytophthora spp. podem ser facilmente confundidos com os de N. haematococca, diferindo pelo fato 
dos cancros no colo e raízes não adquirirem coloração arroxeada. $\mathrm{O}$ patógeno $P$. parasitica também pode ser o responsável por sintomas de damping-off em viveiros de mudas de maracujá como relatado por Cole et al. (1992) e Gonzalez et al. (2000). O micélio de Phytophthora spp. é hialino e cenocítico. Os patógenos produzem esporângios globosos, dentro dos quais formam se zoósporos que, liberados na presença de água, são atraídos por exsudatos radiculares. Atingindo a superfície radicular, os zoósporos encistam e germinam, produzindo hifas que infectam as raízes. P. parasitica produz esporângios papilados e não proliferados (Ho, 1981). Em laboratório, isolados de $P$. parasitica apresentaram diferenças em comportamento de acordo com as diferentes espécies de plantas estudadas. Os isolados de maracujá cresceram mais rapidamente na faixa de temperatura de 28 a $35^{\circ} \mathrm{C}$ e foram os únicos que conseguiram se desenvolver em temperaturas de $37^{\circ} \mathrm{C}$. No campo foi observado que uma maior incidência ocorre quando as temperaturas oscilam entre 26 a $30{ }^{\circ} \mathrm{C}$, havendo um acentuado decréscimo quando as temperaturas estão abaixo de $25^{\circ} \mathrm{C}$ e acima de $35^{\circ} \mathrm{C}$ (Turner, 1974). Ao lado de altas temperaturas, o patógeno requer umidade relativa em torno de $85 \%$. $P$. parasitica já foi relatado como patógeno de citros, berinjela, mamão, tomate, fumo, leucena e cereja, entre outras plantas cultivadas (Van Den Boom \& Huller, 1970).

A morte prematura do maracujazeiro ocorre em focos, disseminando-se de uma planta para sua vizinha, ocorrendo mais em solos argilosos, encharcados e ricos em matéria orgânica. Em solos ácidos, o progresso da doença é acentuado. Na Bahia, Matta (1982) não considerou a doença importante, mas relatou uma maior incidência de $N$. haematococca em solos pesados após longos períodos de chuva e altas temperaturas. A penetração dos patógenos nos tecidos ocorre intra e intercelularmente, destruindo o tecido cortical externo, atingindo o câmbio e impedindo a circulação de seiva. $O$ progresso da lesão, tanto pode ser ascendente, como também atingir o sistema radicular da planta produzindo o escurecimento e apodrecimento do mesmo, refletindo no amarelecimento, queda das folhas e seca da planta.

Plantas novas de maracujá apresentam maior suscetibilidade aos patógenos $N$. haematococca e $P$. parasitica em função da menor espessura da casca no colo e nas raízes, expressando os sintomas de murcha mais rapidamente (Cole et al., 1992). 
Experimentalmente, o número de plantas mortas devido à inoculação com $N$. haematococca foi maior em plantas de 10 semanas de idade do que em plantas de 12 meses de idade. As primeiras apresentaram os sintomas mais cedo, aos 14 dias da inoculação, estando totalmente murchas após seis semanas, enquanto as plantas de um ano de idade demoraram seis meses para morrer (Emechebe \& Mukiibi, 1976). Ferimentos no colo e raízes também aumentam a suscetibilidade à invasão dos patógenos (Cole et al., 1992). Van den Boom \& Huller (1970), Lin \& Chang (1985), Cedeño et al. (1990) e Lutchmeah \& Musaphur (1993) só reproduziram a doença quando foram realizados ferimentos previamente à inoculação. Nas plantas com ferimentos o desenvolvimento do cancro foi sempre maior que naquelas sem ferimentos (Ploetz, 1991). Dentre as metodologias de inoculação dos patógenos adotadas com sucesso na reprodução dos sintomas, destacam-se a imersão das raízes em suspensão de esporos (Cole et al., 1992; Nunes \& Albuquerque, 1995), adição da suspensão de esporos no colo das plantas previamente ferido (Emechebe \& Mukiibi, 1976; Cedeño et al., 1990; Cole et al., 1992) e a fixação de uma cultura micelial, com fita adesiva, no colo das plantas sobre um pequeno ferimento (Delanoë, 1991; Ploetz, 1991). Lin \& Chang (1985) verificaram um maior número de plantas sintomáticas e mortas quando a inoculação foi realizada por disco de micélio comparada à suspensão de esporos no colo da planta. Emechebe \& Mukiibi (1976), testando diferentes métodos de inoculação em que se estudou tipo de inóculo (suspensão de conídios, suspensão de ascósporos, peritécios, massa micelial), em inoculações nas raízes ou no colo das plantas, com ou sem ferimento, verificaram a maior incidência de murcha quando a massa micelial foi depositada no colo das plantas ao nível do solo.

A murcha do maracujazeiro no Zimbábue é uma doença causada pelo complexo dos patógenos $N$. haematococca e $P$. parasitica. O fungo $N$. haematococca foi constantemente isolado de plantas infectadas, mas quando inoculado isoladamente, observou-se que o progresso da doença foi relativamente lento. Na presença da espécie $P$. parasitica, isolada freqüentemente de plantas afetadas com $N$. haematococca, a murcha foi mais devastadora. Plantas de até dois meses de idade mostraram sinais de murcha após três dias de inoculação com $P$. parasitica ou $P$. parasitica mais $N$. 
haematococca, comparado a 16 dias quando N. haematococca foi inoculado sozinho (Cole et al., 1992).

\subsection{Controle da morte prematura}

As medidas profiláticas recomendadas para o controle de $N$. haematococca e $P$. parasitica são evitar o plantio em solos pesados, compactados e ácidos; plantar em leiras altas, evitando-se o acúmulo de água próximo à região do colo; evitar o uso de cobertura morta em épocas de chuvas; evitar ferimentos no ato do coroamento ou capina; utilizar mudas sadias; fazer covas mais profundas, medindo $40 \times 40 \times 40 \mathrm{~cm}$ e proceder à adubação e calagem de forma que os solos infestados com os patógenos não fiquem ácidos ou com excesso de $\mathrm{N}$ e K. Localizado o foco, erradicar as plantas doentes e até duas plantas vizinhas, isolando-se a área e destruindo as plantas erradicadas pelo fogo (Ruggiero et al., 1996).

Com relação ao controle químico de P. parasitica, Matta (1982) recomenda uma avaliação do estádio da lesão no tronco, indicando a cirurgia localizada, nos estádios iniciais da doença, retirando-se os tecidos afetados e aplicando pasta bordalesa. Santos Filho (1993) recomenda, no momento do plantio, mergulhar as plantas até $20 \mathrm{~cm}$ acima das raízes em uma solução de metalaxyl (200 g/100 L de água) e pulverização com fosetyl-Al (250 g/100 L de água), três vezes no período logo após as chuvas de verão. Melo et al. (1990) testaram fosetyl-Al em pulverização foliar com intervalo de 60 dias e metalaxyl em aplicações no solo por encharcamento, sendo a primeira por ocasião do plantio, repetindo-se a cada 120 dias. Avaliaram ainda a influência da matéria orgânica com esterco de galinha e esterco de gado, 5 e $10 \mathrm{Kg} /$ planta, respectivamente. Nenhum dos tratamentos estudados evitou a morte das plantas.

Estudos preliminares, no Pará, com aplicações de benomyl a 500 ppm e captan a 1500 ppm contribuiram para prevenir o avanço das infecções de $N$. haematococca (Nunes \& Albuquerque, 1995). Ponte et al. (1998) constataram que covas tratadas com pentacloronitrobenzeno (PCNB a $75 \%)$ e com $1 \mathrm{Kg}$ de calcário $(\mathrm{CaO})$ exerceram uma eficiente prevenção da morte prematura, com uma redução de 44,7 \% e 48,5 \%, respectivamente. Ponte (1993) obteve um bom índice de controle (75\%) com a 
aplicação de $5 \mathrm{Kg}$ de esterco bovino nas covas. Todavia, isto foi verificado em solo onde espécies de Trichoderma estavam presentes, ao contrário do que Ponte et al. (1998) verificaram com a aplicação de esterco bovino em solo sem a presença constatada de Trichoderma. É sabido que a matéria orgânica estimula o crescimento populacional desses fungos reconhecidos entre os principais antagonistas de espécies do gênero Fusarium. Banhando o colo da planta com oxicloreto de cobre (60 g/20 L de água), em intervalos bissemanais durante um ano, Ssekyewa et al. (1999) obtiveram redução de 65 $\%$ na incidência da morte prematura causada por N. haematococca em Uganda.

Foram encontrados bons resultados de resistência ao patógeno causador da morte prematura com as espécies P. giberti e P. alata (Razera Papa, 1990). No ent anto, $P$. giberti não apresenta frutos com boa qualidade de mercado, nem alta produtividade. Através da enxertia utilizando-se $P$. giberti como porta enxerto e $P$. edulis f. flavicarpa como copa, observoutse resistência à morte prematura, mas com queda de $30 \%$ na produção, em relação ao $P$. edulis f. flavicarpa de pé franco. Com a utilização de $P$. alata como porta enxerto e $P$. edulis f. flavicarpa como copa, observourse resistência à morte prematura, porém suscetibilidade aos nematóides do gênero Meloidogyne. Plantas enxertadas apresentam menor vigor, menor produção e menor capacidade de recuperação após desfolha, devido às doenças e pragas, além de um maior custo de produção e período de formação da muda, sendo portanto recomendável apenas a curto prazo, em situações de emergência, na substituição de plantas mortas ou para plantio em áreas infestadas. Trabalhos de cruzamento visando incorporar a resistência de $P$. alata e P. giberti para $P$. edulis f. flavicarpa evidenciaram a recessividade da resistência, pois os descendentes foram suscetíveis. Outro problema é que com o cruzamento de espécies diferentes os descendentes são praticamente estéreis, dificultando os cruzamentos posteriores. Além disso, a hereditariedade não é isolada para cada característica, ou seja, aumentar a resistência a uma determinada doença pode significar diminuição da tolerância a outras (Razera Papa, 1990). Acredita-se que através de retrocruzamentos sucessivos de P. edulis f. flavicarpa com os descendentes resistentes, originários do cruzamento de uma espécie resistente com P. edulis f. flavicarpa, se consiga uma planta ideal, ou seja, resistente à morte prematura e com boas características de produção. 
Em estudos de resistência a $F$. pallidoroseum e $F$. solani, Delanoë (1991) relatou a ocorrência de resistência em $P$. candida e $P$. fuchsiiflora, enquanto $P$. coccinea, $P$. laurifolia e $P$. glandulosa foram parcialmente resistentes. $\mathrm{O}$ autor citou $P$. cirrhiflora, P. garckei, P. edulis f. flavicarpa e P. edulis var. RL2 como altamente suscetíveis aos patógenos. Algumas linhagens de P. edulis f. flavicarpa apresentarem-se como resistentes a $N$. haematococca quando comparadas a $P$. edulis f. edulis em testes em casa de vegetação (Lin \& Chang, 1985). Segundo Ssekyewa et al. (1999), tanto $P$. edulis f. flavicarpa quanto $P$. maliformis são parcialmente resistentes a $N$. haematococca e podem ser recomendados para uso como porta-enxerto em P.edulis f. edulise híbridos suscetíveis. Cole et al. (1992) relataram a resistência de P. caerulea a $N$. haematococca do marac ujazeiro. Com relação a $P$. parasitica Milne et al. (1975) e Lin \& Chang (1985) observaram que $P$. edulis f. flavicarpa foi resistente, enquanto $P$. edulis f. edulis foi altamente suscetível. No entanto, na África do Sul, a enxertia de P. edulis f. edulis sobre P. edulis f. flavicarpa não foi satisfatória como prática de controle (Grech \& Rijkenberg, 1991). A espécie $P$. caerulea foi relatada como mais resistente a $P$. parasitica que $P$. edulis f. flavicarpa (Terblanche et al., 1987; Grech \& Rijkenberg, 1991; Cole et al., 1992), porém produtores verificaram que nem sempre $P$. caerulea é resistente, apresentando alta variabilidade com relação à resistência a $P$. parasitica. Além disso, Meloidogyne spp. pode afetar a resistência de $P$. caerulea a $P$. parasitica (Grech \& Rijkenberg, 1991).

Cada geração leva um ano e meio para completar-se, o que torna o trabalho de melhoramento muito lento. Uma alternativa interessante, considerando a alta variabilidade da espécie $P$. edulis f. flavicarpa, amplamente cultivada no Brasil, seria a seleção de genótipos resistentes à morte prematura do maracujazeiro. 


\section{MATERIAL E MÉTODOS}

\subsection{Local de execução dos experimentos}

Os ensaios de isolamento, identificação, preparo de inóculo, inoculação, seleção de genótipos resistentes, avaliação de damping -off e podridão de colo e controle químico para os patógenos Nectria haematococca e Phytophthora parasitica foram realizados na Clínica Fitopatológica, no Laboratório de Epidemiologia e na área experimental do Setor de Fitopatologia, pertencentes ao Departamento de Entomologia, Fitopatologia e Zoologia Agrícola da Escola Superior de Agricultura "Luiz de Queiroz”, Universidade de São Paulo, Campus de Piracicaba, SP.

\subsection{Obtenção dos isolados}

Os isolados de $N$. haematococca e $P$. parasitica utilizados nos testes foram provenientes de plantas de maracujá com sintomas de morte prematura, obtidos de consultas enviadas para análise na Clínica Fitopatológica do referido Departamento e de campos comerciais de maracujá. Oito isolados de $N$. haematococca, sendo um procedente de Sussuarana (BA), um de Vera Cruz, um de Monte Azul Paulista, dois de Jaú e três de Populínia (SP) e um isolado de P. parasitica, procedente de Vera Cruz (SP) foram obtidos e tiveram a patogenicidade confirmada em plantas de maracujá-amarelo.

\subsection{Procedimentos experimentais}

\subsubsection{Isolamento e identificação de $N$. haematococca e $P$. parasitica}

Para o isolamento de $N$. haematococca, porções do tecido do colo e raízes de plantas infectadas foram cortadas e desinfectadas em hipoclorito de sódio a $0,5 \%$ por um minuto, lavadas em água destilada e esterilizada, divididas em fragmentos menores e 
plaqueadas em meio de cultura ágar-água (AA). $\mathrm{O}$ isolado de $P$. parasitica foi obtido pela técnica de iscas, em que maracujazeiro foi semeado em solo autoclavado acrescido de pequenos fragmentos do tecido doente do colo e raízes das plantas, procedendo-se o isolamento em AA das porções necróticas, do colo, das plantas tombadas. As colônias desenvolvidas foram repicadas para o meio de cultura batata-dextrose-ágar (BDA) e identificadas com base em comparações morfológicas descritas na literatura (Booth, 1977; Ho, 1981). A produção de peritécios de N. haematococca se iniciou após cerca de 10 dias do plaqueamento do fungo em meio de cultura V8 ou sobre discos de folha de maracujazeiro (Figura 1 - A, B) depositados sobre o meio de cultura a $25{ }^{\circ} \mathrm{C}$ e luz fluorescente contínua.

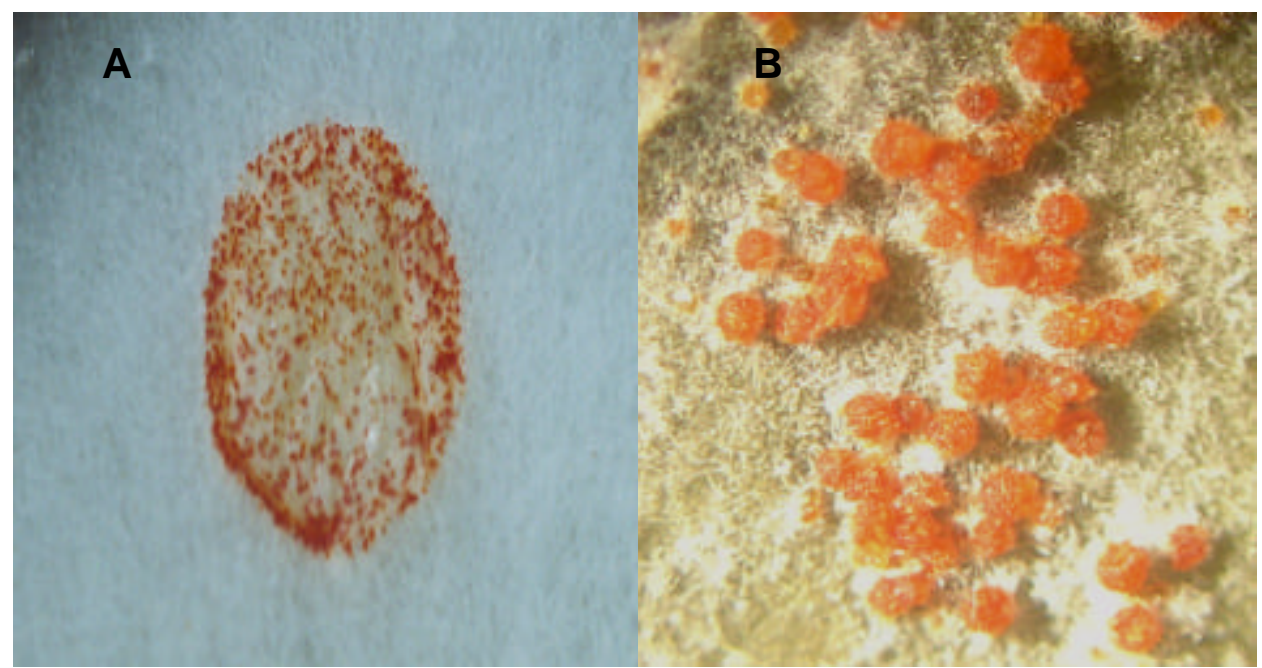

Figura 1 - Peritécios de Nectria haematococca formados sobre discos de folha de maracujazeiro (A) e detalhe dos peritécios em aumento de $30 \mathrm{x}$ (B)

\subsubsection{Teste de patogenicidade}

Plantas de Passiflora edulis f. flavicarpa de três a seis semanas de idade foram inoculadas com um disco de micélio dos patógenos, de cinco milímetros de diâmetro, crescido em BDA, e fixado com fita adesiva sobre um pequeno ferimento circular, de três milímetros de diâmetro, no colo da planta, a uma altura de dois centímetros do solo, removendo-se a fita adesiva após cinco dias (Fischer et al., 2003b). As plantas foram 
mantidas em casa de vegetação, mantendo-se o solo constantemente úmido após a inoculação.

Nos estádios iniciais da doença, as lesões no colo das plantas ocasionadas por $N$. haematococca são de coloração marrom-escura, deprimidas porém, não expõem os tecidos do lenho, enquanto as de $P$. parasitica são mais claras e expõem o lenho na região afetada. Com o avanço da doença, peritécios de coloração avermelhada (Figura 2) surgem sobre as regiões necrosadas por $N$. haematococca. Os sintomas de amarelecimento e murcha só foram observados após o colo das plantas estar completamente anelado.

As plantas foram avaliadas pela presença e desenvolvimento de lesões necróticas, intumescimento do colo, interferência no desenvolvimento vegetativo, além de amarelecimento ou desfolhamento a partir da data de inoculação dos vasos (Ssekyewa et al., 1999). A presença de $N$. haematococca e $P$. parasitica foi confirmada pelo reisolamento dos patógenos das porções sintomáticas.

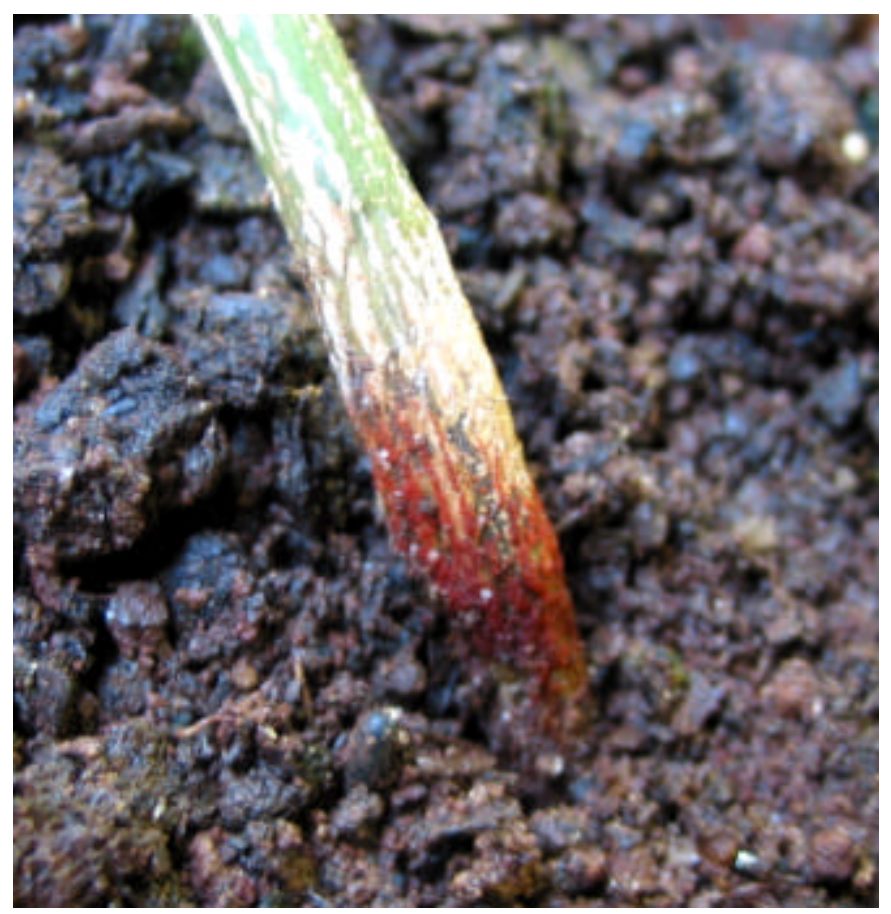

Figura 2 - Peritécios avermelhados de Nectria haematococca sobre o colo necrosado de P. edulis f.flavicarpa 


\subsubsection{Metodologia de inoculação e idade das plantas}

Plantas de $P$. edulis f. flavicarpa com seis semanas pós-germinação, crescidas em vasos contendo solo autoclavado foram inoculadas através de cinco métodos:

1. As raízes foram lavadas e tiveram dois centímetros de suas extremidades cortadas, permanecendo, em seguida, por dez minutos em suspensão de zoósporos $\left(10^{4}\right.$ zoósporos $/ \mathrm{mL})$ de $P$. parasitica ou de conídios $\left(10^{6}\right.$ conídios $\left./ \mathrm{mL}\right)$ de $N$. haematococca em sua fase conidial (adaptado de Cole et al., 1992).

2. Adição de $20 \mathrm{~mL}$ de suspensão de esporos dos patógenos no colo das plantas, nas mesmas concentrações de esporos adotadas no método 1 (adaptado de Lin \& Chang, 1985).

3. Com a finalidade de causar ferimentos no sistema radicular, $15 \mathrm{~cm}$ da lâmina de uma faca foram inseridos no solo a uma distância de dois centímetros do colo das plantas, deslocando-a por toda a extensão do vaso. Em seguida, adicionourse a suspensão de esporos conforme método 2 (adaptado de Lin \& Chang, 1985).

4. Realizou-se um ferimento circular de três milímetros de diâmetro, com auxílio de um furador, no colo das plantas ao nível do solo e adicionourse a suspensão de esporos conforme método 2 (adaptado de Lin \& Chang, 1985).

5. Fixourse com fita adesiva um disco de micélio, de cinco milímetros de diâmetro, crescido em BDA, sobre um ferimento circular de três milímetros de diâmetro no colo das plantas a uma altura de dois centímetros do solo (adaptado de Delanoë, 1991; Fischer et al. 2003b).

A suspensão de conídios de Nectria foi feita em água destilada, raspando-se com uma alça de Drigalsky as placas contendo meio BDA colonizado pelo patógeno por dez dias. Para a produção da suspensão de zoósporos de $P$. parasitica, placas contendo meio V8 colonizadas com o patógeno tiveram as culturas imersas em Solução de Petri por dois dias, com troca diária da solução, para estimular a produção de esporângios (Turner, 1974). No terceiro dia as culturas foram imersas em água destilada e colocadas a $4{ }^{\circ} \mathrm{C}$ por 20 minutos na geladeira para a liberação dos zoósporos do interior dos esporângios. As suspensões de esporos foram ajustadas para as concentrações desejadas comauxílio de um hemocitômetro. 
Para a escolha da idade avaliaram-se plantas com 3, 6, 9 e 12 semanas após a germinação, e dois métodos de inoculação: do sistema radicular (método 1) e do colo da planta (método 5).

Utilizaram-se sementes de P. edulis f. flavicarpa variedade AFRUVEC/Sul Brasil, pois as mesmas originaram plântulas que se mostraram suscetíveis aos patógenos. Testes preliminares com os diferentes isolados de $N$. haematococca evidenciaram maior agressividade do isolado procedente de Vera Cruz (SP), razão pela qual o mesmo foi escolhido como fonte de inóculo para os experimentos.

As plantas foram mantidas em casa de vegetação a $28 \pm 4{ }^{\circ} \mathrm{C}$, mantendo-se o solo constantemente úmido após a inoculação. A distribuição dos vasos no interior da casa de vegetação seguiu um delineamento inteiramente ao acaso, com cinco e seis repetições para os tratamentos de metodologias de inoculação e idade das plantas, respectivamente.

\subsubsection{Avaliação da ocorrência de damping-off e podridão de colo}

Sementes de maracujá foram semeadas, semanalmente, durante cinco semanas, em vasos contendo solo autoclavado, deixando-se após o desbaste 15 plântulas por vaso. Solo autoclavado foi infestado com uma suspensão de esporos e micélio de $N$. haematococca, $P$. parasitica ou $N$. haematococca mais $P$. parasitica, na razão de uma placa de Petri, contendo o meio de cultura BDA, totalmente colonizada, para cada 250 $\mathrm{mL}$ de solo. $\mathrm{O}$ solo misturado com a suspensão dos patógenos foi acondicionado em caixas plásticas e mantido constantemente úmido. Duas semanas após a infestação do solo autoclavado, período este que permite a estabilização da população dos fitopatógenos (Mitchell \& Kannwischer-Mitchell, 1992), o solo foi então, peneirado, homogeneizado e colocado sobre os vasos, na razão de $250 \mathrm{~g}$ de solo infestado por vaso, cobrindo diretamente as sementes da última semeadura ou o colo das plântulas anteriormente semeadas.

Avaliou-se, semanalmente, a incidência de doença, ou seja, o número de plântulas tombadas ou com sintomas terminais de murcha e seca da parte aérea. 


\subsubsection{Comportamento de genótipos de maracujazeiro a $N$. haematococca e $P$. parasitica}

Sementes de diferentes espécies de Passiflora e genótipos de P. edulis f. flavicarpa, procedentes das coleções do Instituto Agronômico de Campinas (IAC), do Campus da Unesp de Jaboticabal, das empresas Maguari e AFRUVEC (Associação dos Fruticultores da Região de Vera Cruz) e do entreposto comercial da CEAGESP (SP), foram semeadas em vasos contendo dois litros de solo autoclavado, deixando-se após o desbaste uma planta por vaso. Plantas de seis semanas pós-germinação foram inoculadas separadamente com um disco de micélio de ambos os patógenos, de cinco milímetros de diâmetro, crescidos em BDA, e fixado com fita adesiva sobre um pequeno ferimento circular, de três milímetros de diâmetro, no colo da planta, a uma altura de dois centímetros do solo, removendo-se a fita adesiva após cinco dias (Fischer et al., 2003b). Após cinco meses da inoculação dos patógenos as espécies de Passiflora sobreviventes foram reinoculadas, conforme método 3 descrito no item 5.3.3, buscando avaliar o comportamento das diferentes Passifloraceas inoculadas via sistema radicular. As plantas foram mantidas em casa de vegetação, buscando manter o solo constantemente úmido após a inoculação. A distribuição dos vasos no interior da casa de vegetação seguiu um delineamento inteiramente ao acaso, com cinco e seis repetições para as espécies de Passifloraceas e genótipos de P. edulis f. flavicarpa, respectivamente.

\subsubsection{Inibição in vitro do crescimento micelial de $N$. haematococca e $P$. parasitica}

Os fungicidas (Tabela 1) foram diluídos em série e ajustados para as concentrações de 0, 1, 10, 100 e 1000 ppm de ingrediente ativo (a concentração de 1000 ppm de i.a. foi utilizada unicamente para $P$. parasitica), adicionados ao meio de cultura BDA fundente, a $45-50{ }^{\circ} \mathrm{C}$, com $20 \mathrm{~mL}$ vertidos em cada placa de Petri de $90 \mathrm{~mm}$ de diâmetro. Após resfriamento do meio, transferiu-se um disco de micélio de cinco milímetros de diâmetro de $N$. haematococca ou $P$. parasitica em crescimento ativo em BDA com aproximadamente sete dias de repicagem.

As placas permaneceram a uma temperatura aproximada de $26{ }^{\circ} \mathrm{C}$, no escuro, por um período de sete dias. A eficiência dos produtos foi verificada através da aferição 
perpendicular dos diâmetros das colônias em milímetros, determinando-se a porcentagem de inibição (\% I) dos tratamentos em relação à testemunha, utilizando-se a fórmula:

$$
\% \mathrm{I}=\frac{\text { diâmetro da testemunha }- \text { diâmetro do tratamento }}{\text { diâmetro da testemunha }} \times 100
$$

O delineamento experimental foi inteiramente casualizado, com cinco repetições, sendo cada parcela representada por uma placa de Petri. Para a análise estatística os dados foram transformados em arc sen $(x / 100)^{1 / 2} \mathrm{e}$ as médias comparadas pelo teste de Tukey a $5 \%$ de probabilidade.

Correlacionando a porcentagem de inibição com o logaritmo da concentração do fungicida foi obtido, graficamente, o valor aproximado da dose efetiva mediana $\left(\mathrm{ED}_{50}\right)$ ou seja, a concentração do produto químico necessária para inibir em $50 \%$ o crescimento micelial do fungo (Edgington et al., 1971).

Após o cálculo da $\mathrm{ED}_{50}$, os fungicidas foram classificados em quatro categorias de eficiência, segundo escala de Bollen \& Fucks (1970), Edgington et al. (1971) e Kataria \& Grover (1978), onde:

a) $\mathrm{ED}_{50}<1$ ppm: altamente eficiente (A.E.).

b) $\mathrm{ED}_{50} 1$ - 10 ppm: moderadamente eficiente (M.E.).

c) $\mathrm{ED}_{50} 10$ - 50 ppm: pouco eficiente (P.E.).

d) $\mathrm{ED}_{50}>50$ ppm: ineficiente (I.).

O experimento foi realizado para os isolados de $N$. haematococca procedentes de Vera Cruz (SP) e Sussuarana (BA) e repetido duas vezes para o isolado de $P$. parasitica procedente de Vera Cruz (SP). 
Tabela 1. Produtos químicos testados quanto à eficiência in vitro no controle de Nectria haematococca ou Phytophthora parasitica do maracujazeiro

\begin{tabular}{|c|c|c|c|}
\hline Nome Comercial & Nome Técnico & Classe & $\begin{array}{l}\text { Concentração do } \\
\text { i.a. }(\mathrm{g} / \mathrm{Kg} \text { ou } \mathrm{g} / \mathrm{l})\end{array}$ \\
\hline Aliette $^{(2)}$ & fosetyl-AI & sistêmico & 800 \\
\hline Amistar $500 \mathrm{WG}^{(1)}$ & azoxystrobin & sistêmico & 500 \\
\hline Anvil 100 SC ${ }^{(1)}$ & hexaconazole & sistêmico & 100 \\
\hline Benlate $500^{(1)}$ & benomyl & sistêmico & 500 \\
\hline Captan $500 \mathrm{PM}^{(3)}$ & captan & contato & 500 \\
\hline Cercobin $700 \mathrm{PM}^{(1)}$ & tiofanato metílico & sistêmico & 700 \\
\hline Curzate $M+$ Zinco $^{(2)}$ & cymoxanil+maneb & sistêmico+contato & $80+640$ \\
\hline Dacostar $500^{(3)}$ & chlorothalonil & contato & 500 \\
\hline Derosal $500 \mathrm{SC}^{(1)}$ & carbendazim & sistêmico & 500 \\
\hline Folio Gold ${ }^{(2)}$ & metalaxyl+chlorothalonil & sistêmico+contato & $67,5+675$ \\
\hline Forum $^{(2)}$ & dimethomorph & sistêmico & 500 \\
\hline Frowcide $^{(3)}$ & fluazinam & contato & 500 \\
\hline Hokko Suzu $200^{(2)}$ & trifenil acetato de estanho & contato & 200 \\
\hline $\mathrm{KIF}^{(2)(*)}$ & kif & sistêmico & 100 \\
\hline Manzate $800^{(3)}$ & mancozeb & contato & 800 \\
\hline $\operatorname{Maxim}^{(3)}$ & fluodioxonil & sitêmico & 25 \\
\hline Moncerem $\mathrm{PM}^{(1)}$ & pencycurom & contato & 250 \\
\hline Previcur $\mathrm{N}^{(2)}$ & promocarb & sistêmico & 722 \\
\hline $\operatorname{Recop}^{(3)}$ & oxicloreto de cobre & contato & 500 \\
\hline Ridomil Gold $\mathrm{MZ}^{(2)}$ & metalaxyl+mancozeb & sistêmico+contato & $40+640$ \\
\hline Rhodiauram SC ${ }^{(3)}$ & thiram & contato & 500 \\
\hline Rovral SC ${ }^{(3)}$ & iprodione & sistêmico & 500 \\
\hline Sialex $500^{(1)}$ & procimidone & sistêmico & 500 \\
\hline Spectro $^{(1)}$ & difenoconazole & sistêmico & 150 \\
\hline Sportak $450 \mathrm{CE}^{(3)}$ & prochloraz & sistêmico & 450 \\
\hline Stroby $\mathrm{SC}^{(3)}$ & kresoxim metil & contato & 500 \\
\hline Tecto $600^{(3)}$ & thiabendazole & sistêmico & 600 \\
\hline Tegram $^{(3)}$ & thiram+ thiabendazole & contato+sistêmico & $350+80$ \\
\hline Vitavax+Thiram $^{(1)}$ & carboxin+thiram & sistêmico+contato & $375+375$ \\
\hline Trifmine $^{(1)}$ & triflumizole & sistêmico & 300 \\
\hline
\end{tabular}

\subsubsection{Tratamento químico erradicante em solo infestado}

Solos autoclavados foram infestados com uma suspensão de micélio e esporos de $N$. haematococca e $P$. parasitica, na razão de uma placa de Petri colonizada para cada $250 \mathrm{~mL}$ de solo. Quatorze dias após, o solo foi peneirado, homogeneizado e 100 $\mathrm{mL}$ do solo infestado foi transferido para sacos plásticos, de um litro de capacidade, 
contendo uma plântula de maracujá-amarelo, variedade Sul Brasil, de cinco semanas de idade. Em seguida, estes receberam os seis produtos químicos que se mostraram mais eficientes no controle in vitro, visando erradicar os patógenos (Tabela 2). As doses utilizadas de cada produto foram baseadas nas recomendações para outras culturas considerando os mesmos não estarem registrados para o maracujazeiro. O fungicida benomyl, embora também eficiente na inibição do crescimento micelial de $N$. haematococca (Tabela 8) foi desconsiderado em função do uso do mesmo estar proibido no Brasil pelo Ministério da Saúde. Após uma semana, as plântulas sofreram ferimentos, de três milímetros de diâmetro, com auxílio de um furador, no colo ao nível do solo. Nesse caso, o desenvolvimento da doença foi avaliado conforme item 3.3.2. Além disso, o solo infestado foi semeado com P. edulis f. flavicarpa, avaliando-se a germinação, emergência e desenvolvimento das plântulas, conforme parâmetros descritos no item 3.3.4.

\subsubsection{Tratamento químico curativo}

Maracujazeiros variedade Sul-Brasil de cinco semanas de idade foram inoculados com uma suspensão de esporos na região do colo previamente ferido (método 4 do item 3.3.3). As plantas receberam, aos dois e sete dias após a inoculação, um tratamento químico com os fungicidas sistêmicos que se mostraram mais eficientes in vitro (Tabela 2), por meio de rega na região do colo, acima do ponto de inoculação, buscando inibir o desenvolvimento da doença. Fosetyl-Al embora tenha mostrado baixa inibição do crescimento micelial in vitro de $P$. parasitica (Tabela 9), foi utilizado in vivo onde sua eficiência é considerada superior (Cohen \& Coffey, 1986). A avaliação da eficiência dos tratamentos químicos no controle da doença foi feita conforme metodologia descrita em 3.3.2, durante quatro meses. 
Tabela 2. Fungicidas comparados quanto à eficiência in vivo no tratamento químico erradicante e curativo de Nectria haematococca e Phytophthora parasitica em plantas de maracujá-amarelo

\begin{tabular}{|c|c|c|c|}
\hline Nome Técnico & Princípio de atuação & Formulação & $\begin{array}{l}\text { Dose }(\mathrm{g} \text { ou } \mathrm{ml} \text { de } \\
\left.\text { p.c. } / 100 \mathrm{~L} \mathrm{H}_{2} \mathrm{O}\right)\end{array}$ \\
\hline captan & erradicante & pó molhável & 240 \\
\hline carbendazim $^{1}$ & errad./curativo & susp. concentrada & 100 \\
\hline cymoxanil+maneb $^{2}$ & errad./curativo & pó molhável & 250 \\
\hline difenoconazole $^{1}$ & curativo & susp. concentrada & 70 \\
\hline dimethomorph $^{2}$ & errad./curativo & pó molhável & 150 \\
\hline fosetyl-Al ${ }^{2}$ & curativo & pó molhável & 250 \\
\hline $\mathrm{kif}^{2}$ & errad./curativo & susp. concentrada & 100 \\
\hline mancozeb $^{2}$ & erradicante & pó molhável & 200 \\
\hline metalaxyl+mancozeb ${ }^{2}$ & errad./curativo & pó molhável & 300 \\
\hline oxicloreto de cobre ${ }^{2}$ & erradicante & pó molhável & 300 \\
\hline prochloraz $^{1}$ & errad./curativo & conc. emulsionável & 150 \\
\hline thiram+thiabendazole ${ }^{1}$ & erradicante & susp. concentrada & 200 \\
\hline thiabendazole $^{1}$ & errad./curativo & pó molhável & 300 \\
\hline triflumizole $^{1}$ & errad./curativo & pó molhável & 70 \\
\hline
\end{tabular}

Testado para N. haematococca.

${ }^{2}$ Testado para P. parasitica. 


\section{RESULTADOS}

\subsection{Metodologia de inoculação e idade das plantas}

As lesões no colo das plantas inoculadas pelos métodos 4 e 5 tornaram-se visíveis aos sete dias após a inoculação. Algumas plantas apresentaram murcha seguida de morte principalmente nos quatro primeiros meses, com início a partir da quarta semana. Os sintomas de podridão do colo e raízes nas plantas inoculadas pelos métodos 1 e 3 foram mais tardios, ocorrendo a partir do segundo mês. Seis meses após a inoculação, os sintomas praticamente cessaram com a cicatrização das lesões e a sobrevivência das plantas restantes.

Os métodos 4 e 5 foram os que apresentaram maior número de plantas mortas e comprimento de lesões no colo para ambos os patógenos nas duas épocas/repetições do experimento (Tabela 3). A doença não ocorreu nos dez meses de avaliação quando $N$. haematococca foi inoculado na ausência de ferimentos (método 3). De maneira geral, a intensidade da doença para ambos os patógenos foi maior quando as plantas foram inoculadas em março de 2002 comparado a maio do mesmo ano, devido provavelmente às temperaturas maiores, com médias de $28{ }^{\circ} \mathrm{C}$ em março e $26{ }^{\circ} \mathrm{C}$ em maio, sob casa de vegetação. 
Tabela 3. Comprimento $(\mathrm{cm})$ de lesões ou morte da planta (+) após a inoculação com Nectria haematococca e Phytophthora parasitica em diferentes métodos de inoculação, realizados em março e maio de 2002

\begin{tabular}{|c|c|c|c|c|c|c|c|c|c|c|}
\hline \multirow{3}{*}{ Patógeno } & \multicolumn{10}{|c|}{ Métodos de inoculação** } \\
\hline & \multicolumn{2}{|c|}{1} & \multicolumn{2}{|c|}{2} & \multicolumn{2}{|c|}{3} & \multicolumn{2}{|c|}{4} & \multicolumn{2}{|c|}{5} \\
\hline & \multicolumn{2}{|c|}{$10 / 0327 / 05$} & \multicolumn{2}{|c|}{$10 / 0327 / 05$} & \multicolumn{2}{|c|}{$10 / 0327 / 05$} & \multicolumn{2}{|c|}{$10 / 0327 / 05$} & \multicolumn{2}{|c|}{$10 / 0327 / 05$} \\
\hline \multicolumn{11}{|c|}{ N. haematococca } \\
\hline $1 *$ & + & 0,0 & 0,0 & 0,0 & + & + & + & + & + & + \\
\hline 2 & + & 0,0 & 0,0 & 0,0 & 2,0 & 1,4 & + & 2,6 & + & + \\
\hline 3 & 0,0 & 0,0 & 0,0 & 0,0 & 1,1 & 0,0 & + & 2,5 & + & 1,3 \\
\hline 4 & 0.0 & 0.0 & 0.0 & 0.0 & 0.0 & 0.0 & 2.1 & 0,9 & 2.8 & 1.2 \\
\hline 5 & 0,0 & 0,0 & 0,0 & 0,0 & 0,0 & 0,0 & 1,5 & 0,7 & 2,6 & 1,2 \\
\hline \multicolumn{11}{|l|}{$P$. parasitica } \\
\hline 1 & + & + & + & 0,0 & + & 1,2 & + & + & + & + \\
\hline 2 & + & 2,3 & + & 0,0 & + & 0,0 & + & + & + & + \\
\hline 3 & + & 0,7 & 0,0 & 0,0 & 0,0 & 0,0 & + & + & + & + \\
\hline 4 & 1,0 & 0,0 & 0,0 & 0,0 & 0,0 & 0,0 & + & 2,7 & 3,0 & 3,7 \\
\hline 5 & 0,0 & 0,0 & 0,0 & 0,0 & 0,0 & 0,0 & 3,2 & 2,4 & 2,5 & 2,2 \\
\hline
\end{tabular}

* Repetição = planta de P. edulis f. flavicarpa.

** Métodos descritos no item 3.3.3.

O número de plantas mortas e o tamanho das lesões foram decrescentes com a idade para ambos os patógenos, com maior mortalidade em plantas inoculadas com idade de 3 semanas após a germinação, seguida de plantas com 6 e 9 semanas. Plantas novas também morreram mais rapidamente. $N$. haematococca não acarretou a murcha e morte das plantas de 9 semanas e nenhum patógeno causou a morte em plantas de 12 semanas pós-germinação nas duas metodologias de inoculação adotadas, durante dez meses de avaliação do experimento. A doença foi mais severa, para ambos os patógenos, nas inoculações realizadas em março (Tabela 4), quando as temperaturas foram mais elevadas. 
Tabela 4. Comprimento $(\mathrm{cm})$ de lesões ou morte da planta (+) após a inoculação com Nectria haematococca e Phytophthora parasitica em plantas de maracujazeiro de diferentes idades

\begin{tabular}{|c|c|c|c|c|c|c|c|}
\hline \multirow{2}{*}{$\begin{array}{l}\text { Semanas pós- } \\
\text { germinaçãa }\end{array}$} & \multirow[t]{2}{*}{ Rep. } & \multicolumn{3}{|c|}{ N. haematococca } & \multicolumn{3}{|c|}{ P. parasitica } \\
\hline & & $\begin{array}{c}5^{a} \\
03 / 2002\end{array}$ & $\begin{array}{c}5 \\
06 / 2002\end{array}$ & $\begin{array}{c}1^{b} \\
06 / 2002\end{array}$ & $\begin{array}{c}5 \\
03 / 2002\end{array}$ & $\begin{array}{c}5 \\
06 / 2002\end{array}$ & $\begin{array}{c}1 \\
06 / 2002\end{array}$ \\
\hline \multirow[t]{6}{*}{3} & $T$ & + & + & 0,0 & + & + & + \\
\hline & 2 & + & + & 0,0 & + & + & + \\
\hline & 3 & + & + & 0,0 & + & + & 2,6 \\
\hline & 4 & + & 2,4 & 0,0 & + & + & 0,0 \\
\hline & 5 & 2,1 & 1,1 & 0,0 & + & 2,5 & 0,0 \\
\hline & 6 & 2,1 & 1,0 & 0,0 & + & 1,3 & 0,0 \\
\hline \multirow[t]{6}{*}{6} & 1 & + & + & 2,4 & + & + & + \\
\hline & 2 & + & 2,7 & 1,0 & + & 3,6 & 3,1 \\
\hline & 3 & 3,4 & 2,3 & 0,0 & + & 3,6 & 0,0 \\
\hline & 4 & 2,7 & 1,2 & 0,0 & + & 2,0 & 0,0 \\
\hline & 5 & 2,6 & 1,0 & 0,0 & 4,0 & 1,5 & 0,0 \\
\hline & 6 & 2,5 & 0,9 & 0,0 & 4,0 & 1,5 & 0,0 \\
\hline \multirow[t]{6}{*}{9} & 1 & 3,4 & 2,5 & 0,0 & + & + & + \\
\hline & 2 & 3,1 & 2,2 & 0,0 & + & 4,4 & + \\
\hline & 3 & 2,9 & 1,2 & 0,0 & 3,0 & 3,1 & 0,0 \\
\hline & 4 & 2,8 & 0,8 & 0,0 & 3,0 & 2,9 & 0,0 \\
\hline & 5 & 2,8 & 0,7 & 0,0 & 2,4 & 2,2 & 0,0 \\
\hline & 6 & 2,5 & 0,7 & 0,0 & 1,8 & 1,9 & 0,0 \\
\hline \multirow[t]{6}{*}{12} & 1 & 2,9 & 2,2 & 0,0 & 2,4 & 1,3 & 1,2 \\
\hline & 2 & 2,8 & 1,4 & 0,0 & 2,1 & 1,2 & 0,0 \\
\hline & 3 & 2,6 & 1,4 & 0,0 & 2,0 & 1,1 & 0,0 \\
\hline & 4 & 2,1 & 1,2 & 0,0 & 1,8 & 0,9 & 0,0 \\
\hline & 5 & 2,0 & 1,0 & 0,0 & 1,5 & 0,8 & 0,0 \\
\hline & 6 & 1,5 & 0,8 & 0,0 & 1,5 & 0,6 & 0,0 \\
\hline
\end{tabular}

${ }^{a}$ Método 5 de inoculação (descrito em 3.3.3).

${ }^{\mathrm{b}}$ Método 1 de inoculação (descrito em 3.3.3).

\subsection{Damping-off e podridão de colo de $P$. edulis f. flavicarpa}

Observou-se uma redução crescente no número de plântulas mortas a partir da semeadura resultante do ataque dos patógenos $P$. parasitica e $N$. haematococca $+P$. parasitica (Tabela 5). N. haematococca quando inoculado isoladamente não causou doença, porém quando em associação a $P$. parasitica o número de plantas mortas foi superior ao provocado por $P$. parasitica isoladamente como confirmado estatisticamente 
pelo teste $\mathrm{F}(\mathrm{F}=17,43 ; \mathrm{P}=0,000)$ (Tabela 5). As plantas foram avaliadas semanalmente durante quatro meses, considerando que no último mês não ocorreu a morte de plantas.

Tabela 5. Plântulas mortas de $P$. edulis f. flavicarpa, após a inoculação de $N$. haematococca e $P$. parasitica isolada e conjuntamente em plântulas de diferentes idades

\begin{tabular}{lccccc}
\hline Patógenos & \multicolumn{5}{c}{ Idade das plântulas na inoculação } \\
\cline { 2 - 6 } & Semeadura & Emergência & 1 semana & 2 semanas & 3 semanas \\
\hline N. haematococca & $0 *$ & 0 & 0 & 0 & 0 \\
N. haematococca & 6,33 & 6,67 & 3,33 & 3,67 & 1 \\
+ P. parasitica & & & & & \\
$P$. parasitica & 4,33 & 2 & 1,33 & 1,00 & 1,33 \\
\hline * Média de três vasos contendo cada vaso 15 plântulas.
\end{tabular}

* Média de três vasos contendo cada vaso 15 plântulas.

\subsection{Comportamento de Passifloraceas}

Verificou-se o desenvolvimento das lesões a partir do quinto dia da inoculação para as espécies mais suscetíveis e a morte de plantas a partir da terceira semana, cessando praticamente o crescimento das lesões após três meses para a maioria das espécies, com a cicatrização das lesões. Após a inoculação do sistema radicular, realizada cinco meses após a inoculação no colo das plantas, ocorreu a morte de uma repetição das espécies $P$. caerulea, $P$. sidaefolia, $P$. maliformes, $P$. suberosa e $P$. setacea causada por $N$. haematococca. Nas duas últimas espécies, as plantas sobreviventes apresentaram intumescimento do colo ao nível do solo. As espécies $P$. nitida (Figura 3 A), P. laurifolia (Figura 3 - B) e P. alata (Figura 3 - C) apresentaram as menores médias de lesões de $N$. haematococca, de 0,8, 0,85 e 0,92 cm de comprimento (Tabela 6), respectivamente; enquanto que para $P$. parasitica foram as espécies $P$. suberosa (Figura 4 - A), P. foetida (Figura 4 - B) e P. morifolia (Figura 4 - C) as menos afetadas, com médias de lesões de $0,5,0,56$ e $0,72 \mathrm{~cm}$ de comprimento (Tabela 6), respectivamente. $P$. sidaefolia, P. edulis f. flavicarpa (Figuras 5 - A, B e C) e P. edulis f. edulis foram as mais suscetíveis a ambos os patógenos, com sintomas que culminaram com a morte de plantas, após três semanas da inoculação. Adicionalmente, $P$. pohlii, P. setacea, $P$. cincinnata, $P$. caerulea, $P$. suberosa e $P$. maliformis apresentaram suscetibilidade a $N$. 
haematococca, e P. setacea e P. alata apresentaram suscetibilidade a $P$. parasitica. As plantas sobreviventes aos patógenos não apresentaram redução no desenvolvimento vegetativo comparado às plantas sadias, não inoculadas com os patógenos, nas condições experimentais de casa de vegetação.

Tabela 6. Comprimento $(\mathrm{cm})$ de lesões e número de Passifloraceas mortas, um ano após a inoculação com Nectria haematococca e Phytophthora parasitica

\begin{tabular}{|c|c|c|c|c|}
\hline Passiflora* & N.haematococca & PI. mortas & P.parasitica & Pl. mortas \\
\hline P. nitida (IAC-Campinas) & $0,80 \mathrm{a}$ & 0 & $1,53 \mathrm{abcd}$ & 0 \\
\hline P. laurifolia (Unesp-Jaboticabal) & 0,85 a & 0 & 1,12 abcd & 0 \\
\hline P. alata (Conchal) & $0,92 \mathrm{a}$ & 0 & 1,38 abcd & 1 \\
\hline$P$. alata (São Miguel Arcanjo) & $0,92 \mathrm{a}$ & 0 & $1,76 \mathrm{bcd}$ & 0 \\
\hline P. alata (Esalq - Dep. Genética) & $1,08 \mathrm{a}$ & 0 & $1,93 \mathrm{~cd}$ & 1 \\
\hline P. maliformis (IAC) & $1,10 \mathrm{a}$ & 1 & $0,73 a b$ & 0 \\
\hline P. coccinea (IAC) & $1,26 \mathrm{a}$ & 0 & $2,16 \quad \mathrm{~d}$ & 0 \\
\hline P. suberosa (Esalq) & $1,30 \mathrm{a}$ & 1 & $0,50 \mathrm{a}$ & 0 \\
\hline P. morifolia (Unesp) & $1,32 \mathrm{a}$ & 0 & $0,72 a b$ & 0 \\
\hline P. quadrangularis (IAC) & 1,33 a & 0 & $1,00 a b c$ & 0 \\
\hline P. digitata (IAC) & $1,40 \mathrm{ab}$ & 0 & 1,18 abcd & 0 \\
\hline P. caerulea (IAC) & $1,44 \mathrm{ab}$ & 1 & 1,38 abcd & 0 \\
\hline P. cincinnata (IAC) & $1,63 \mathrm{abc}$ & 1 & $0,78 \mathrm{ab}$ & 0 \\
\hline P. setacea (Unesp) & $1,70 \mathrm{abc}$ & 1 & $1,98 \mathrm{~cd}$ & 1 \\
\hline P. e. edulis (IAC) & $1,98 \mathrm{abc}$ & 1 & $3,00 * *$ & 3 \\
\hline P. foetida (Esalq) & 2,52 bc & 0 & $0,56 a b$ & 0 \\
\hline P. giberti (Esalq) & 2,60 bc & 0 & 1,08 abcd & 0 \\
\hline P. pohlii (IAC) & 2,70 & 1 & 1,23 abcd & 0 \\
\hline P. sidaefolia (IAC) & $1,50 * *$ & 4 & $1,40 * *$ & 2 \\
\hline P. e. flavicarpa (AFRUVEC) & $2,13 * *$ & 2 & $2,40 * *$ & 4 \\
\hline C.V. $(\%)$ & 33,97 & & 37,14 & \\
\hline
\end{tabular}

Média de 5 repetições. Médias seguidas por letras iguais não diferem entre si (Tukey, $\mathrm{p}<0,05)$.

* Espécie (procedência).

**Média das plantas sobreviventes. 


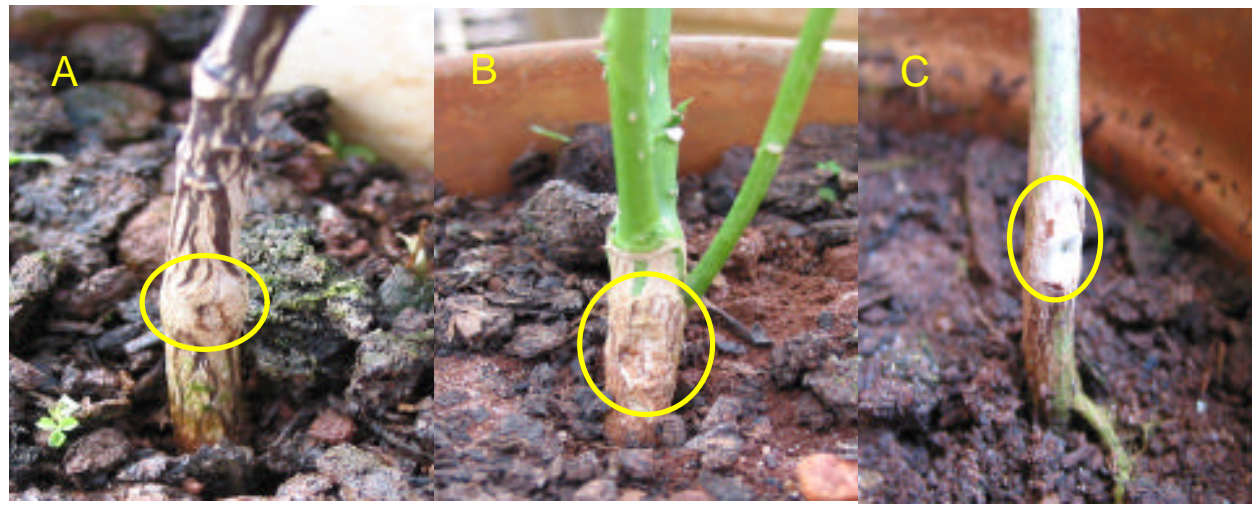

Figura 3 - Lesões de Nectria haematococca inoculado por deposição de disco de micélio sobre ferimento no colo das plantas das espécies $P$. nitida (A), P. laurifolia (B) e P. alata $(\mathrm{C})$

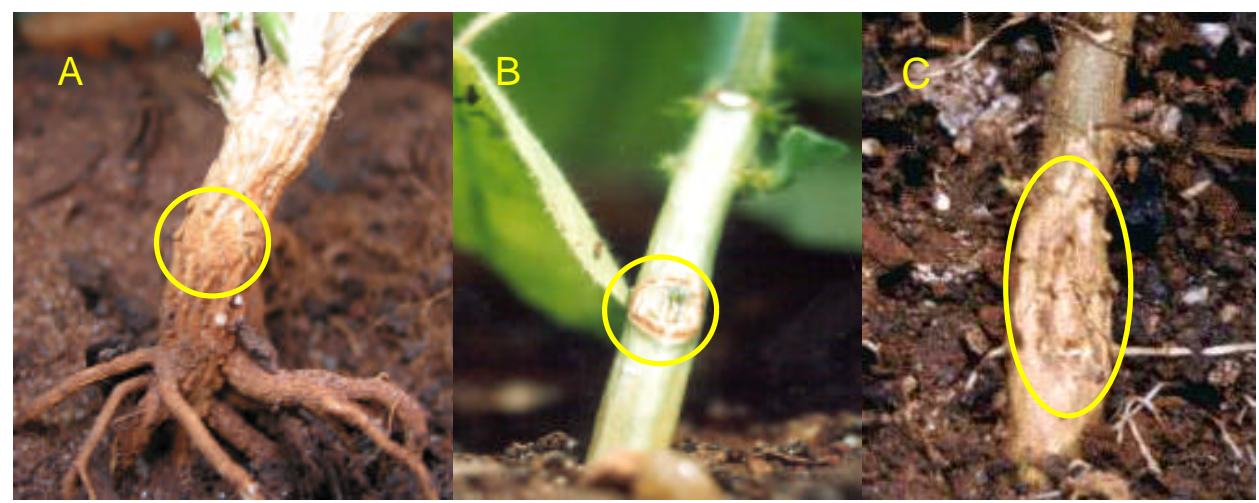

Figura 4 - Lesões de Phytophthora parasitica inoculado por deposição de disco de micélio sobre ferimento no colo das plantas das espécies $P$. suberosa (A), P. foetida (B) e P. morifolia (C)

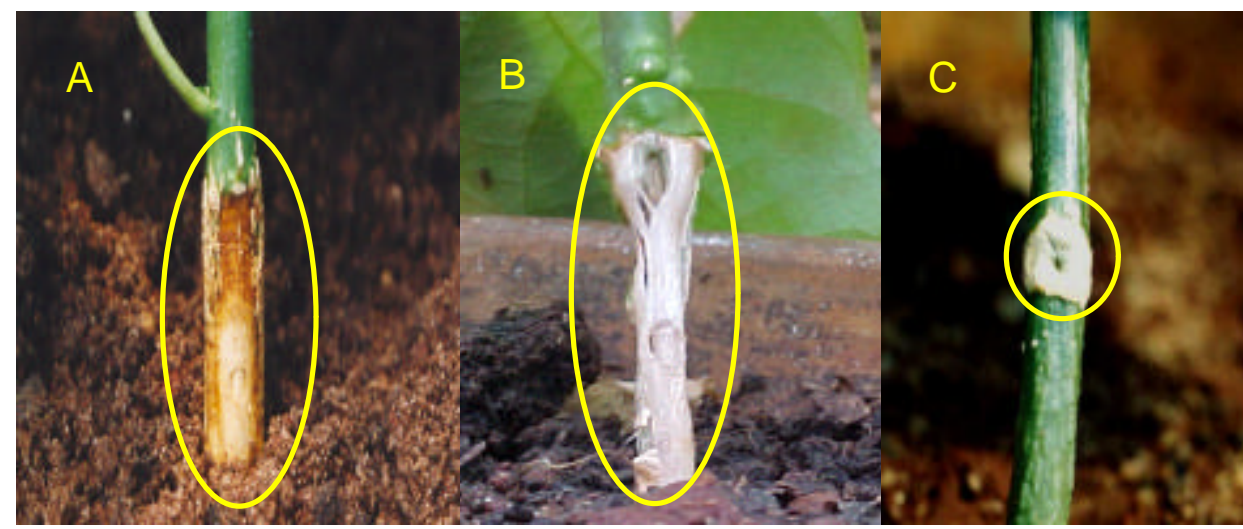

Figura 5 - Lesões de $N$. haematococca (A) e de $P$. parasitica (B) e testemunha sadia (C) inoculado por deposição de disco de micélio ou disco de BDA sobre ferimento no colo das plantas de P. edulis f flavicarpa 


\subsection{Comportamento de genótipos de $P$. edulis f. flavicarpa}

Observou-se o desenvolvimento das lesões a partir do quinto dia da inoculação em algumas plantas para ambos os patógenos. Os sintomas de murcha e morte das plantas iniciaram-se a partir da segunda semana com o patógem $P$. parasitica e a partir da terceira semana com $N$. haematococca. O comprimento das lesões e o número de plantas mortas pouco se alteraram após seis semanas nas inoculações com $P$. parasitica. As lesões ocasionadas por $N$. haematococca cessaram o crescimento apenas após oito semanas, considerando que lesões acima de 2,5 praticamente atingiram o nível do solo, não permitindo, conseqüentemente, avaliar o crescimento descendente das mesmas em direção ao sistema radicular. Embora o número de plantas mortas tenha se concentrado nos três primeiros meses após a inoculação para os dois patógenos, algumas plantas morreram nos meses seguintes devido ao ataque dos patógenos.

Observou-se alta variabilidade dos diferentes genótipos para com os dois patógenos (Tabela 7). Destaca-se a existência de genótipos mais resistentes a $N$. haematococca, como Morretes (PR) com comprimento médio de lesão de 1,65 cm, seguido por "Maguari" (MG) e Sapucaí (SP), com 2,18 e 2,37 cm de comprimento médio, respectivamente, enquanto que para $P$. parasitica foram os genótipos Morretes (PR), Jaboticabal (SP), LE13P2 (IAC) e Sapucaí (SP) as menos afetadas com média de lesões de 1,2, 1,2, 1,43 e 1,5 cm de comprimento (Tabela 7). "SulBrasil" (SP) e Livramento (BA) podem ser considerados altamente suscetíveis a ambos os patógenos, com sintomas que culminaram com a morte de plantas. Amparo (SP), IAC 270, Jaboticabal (SP), Monte Alegre do Sul (SP) foram suscetíveis a $N$. haematococca e "Maguari" (MG), Itapetininga e Adamantina (SP) suscetíveis a P. parasitica por apresentarem duas ou mais repetições mortas. 
Tabela 7. Comprimento $(\mathrm{cm})$ de lesões e número de plantas de $P$. edulis f. flavicarpa mortas, dez meses após a inoculação com $N$. haematococca e $P$. parasitica

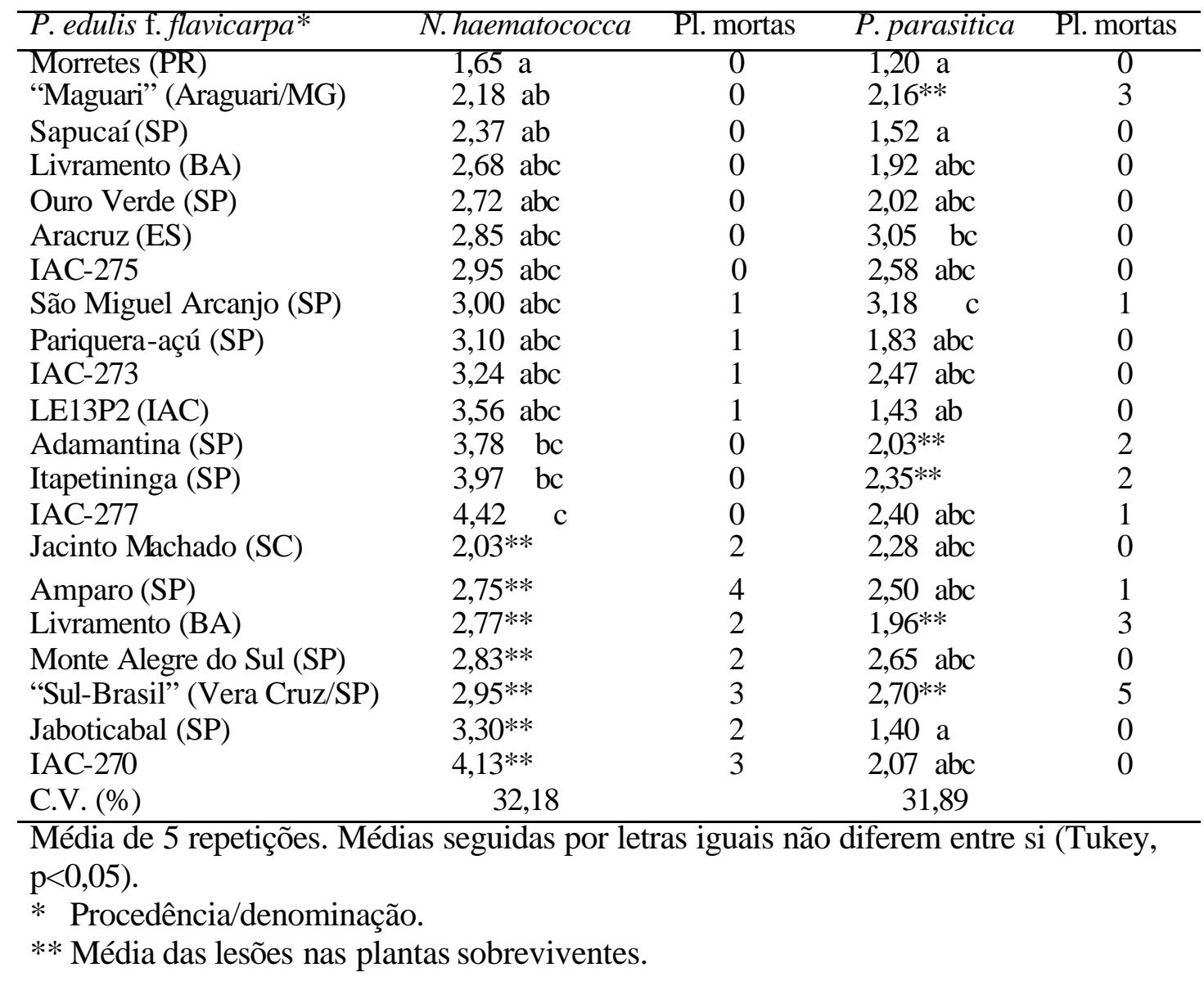

\subsection{Inibição in vitro do crescimento micelial de $N$. haematococca}

As porcentagens de inibição (\% I) dos 22 fungicidas testados in vitro, a 1, 10 e 100 ppm, para os isolados de N. haematococca procedentes de Vera Cruz (SP), e Sussuarana (BA), podem ser visualizadas na Tabela 8. Através da \% I a diferentes concentrações foi determinada a $\mathrm{ED}_{50}$ dos respectivos fungicidas (Tabela 9).

Verifica-se que os isolados de Vera Cruz (SP) e de Sussuarana (BA) foram semelhantes quanto à sensibilidade aos fungicidas. Analisando-se os dados a 100 ppm observa-se que somente prochloraz inibiu totalmente o crescimento micelial dos dois isolados de $N$. haematococca. Os produtos thiabendazole, thiram+thiabendazole, 
benomyl e carbendazim também foram altamente eficientes ( $\left.\mathrm{ED}_{50}<1 \mathrm{ppm}\right)$. Outros fungicidas como o fluazinam, iprodione e fluodioxonil embora também apresentassem $\mathrm{ED}_{50}<1 \mathrm{ppm}$ demonstraram porcentagem de inibição inferior estatisticamente (Tabela 8 e 9).

Tabela 8. Porcentagem de inibição do crescimento micelial de $N$. haematococca a diferentes fungicidas e concentrações

\begin{tabular}{|c|c|c|c|c|c|c|c|c|c|c|c|c|}
\hline \multirow{2}{*}{$\begin{array}{l}\text { Ingrediente } \\
\text { Ativo }\end{array}$} & \multicolumn{6}{|c|}{ N. haematococca (Vera Cruz, SP) } & \multicolumn{6}{|c|}{ N. haematococca(Sussuarana/BA) } \\
\hline & \multicolumn{2}{|c|}{$1 \mathrm{ppm}$} & \multicolumn{2}{|c|}{$10 \mathrm{ppm}$} & \multicolumn{2}{|c|}{$100 \mathrm{ppm}$} & \multicolumn{2}{|c|}{$1 \mathrm{ppm}$} & \multicolumn{2}{|c|}{$10 \mathrm{ppm}$} & \multicolumn{2}{|c|}{$100 \mathrm{ppm}$} \\
\hline Prochloraz & $78,82 \mathrm{a}$ & & 93,95 & & 100,0 & & 84,77 & & 98,94 & & 100,00 & \\
\hline Thiabendazole & $78,95 \mathrm{a}$ & & 84,34 & & 97,63 & & 80,69 & & 86,58 & $\mathrm{~b}$ & 96,38 & $a^{(2)}$ \\
\hline Thiram+thiabend. & $81,32 \mathrm{a}$ & & 86,45 & & 94,11 & & 67,51 & $\mathrm{c}$ & 81,75 & $\mathrm{~b}$ & $96,83 a$ & \\
\hline Benomyl & $65,00 \mathrm{~b}$ & & 88,03 & & 92,76 & & 67,27 & $\mathrm{c}$ & 88,84 & & 93,82 & \\
\hline Carbendazim & $68,95 \mathrm{~b}$ & & 85,79 & & 90,79 & & 77,68 & b & 88,24 & & 91,10 & \\
\hline Triflumizole & 28,95 & $\mathrm{~g}$ & 52,89 & bed & 75,66 & b & 25,07 & $\mathrm{~h}$ & 48,24 & def & 71,34 & $\mathrm{c}$ \\
\hline Captan & $-0,92$ & $\mathrm{i}$ & 1,84 & $\mathrm{~h}$ & 64,34 & $\mathrm{~cd}$ & 13,75 & $\mathrm{ij}$ & 21,87 & $\mathrm{i}$ & 68,63 & \\
\hline Tiofanato metílico & 1,84 & hi & 42,37 & def & 67,76 & $\mathrm{bc}$ & 2,71 & $\operatorname{lm}$ & 46,00 & defg & 63,20 & $\mathrm{~d}$ \\
\hline Thiram+ & 1,05 & hi & 11,84 & gh & 53,29 & fg & 9,20 & $\mathrm{jk}$ & 22,32 & $\mathrm{i}$ & 62,74 & d \\
\hline Difer & 35,00 & $\mathrm{f}$ & 46,05 & cdef & 64,74 & $\mathrm{~cd}$ & 30,69 & $\mathrm{~g}$ & 46,84 & defg & 55,81 & \\
\hline Hexa & 44,21 & $\mathrm{e}$ & 48,29 & cdef & 56,58 & defg & 43,74 & $\mathrm{f}$ & 53,08 & $\mathrm{de}$ & 59,28 & de \\
\hline Fluazi & 56,84 & $\mathrm{~d}$ & 56,58 & bc & 61,84 & cde & 50,07 & e & 53,24 & de & 57,62 & \\
\hline Thira & 5,92 & $\mathrm{~h}$ & 17,37 & g & 58,55 & def & 9,50 & $\mathrm{jk}$ & 33,34 & ghi & 58,52 & \\
\hline Iprod & 60,79 & $\mathrm{~cd}$ & 61,18 & & 56,84 & defg & 56,26 & $\mathrm{~d}$ & 57,16 & $\mathrm{~cd}$ & 57,47 & \\
\hline Chlc & 27,63 & $\mathrm{~g}$ & 44,74 & cdef & 54,34 & efg & 28,51 & gh & 55,98 & $\mathrm{~cd}$ & 57,92 & \\
\hline & 4,87 & $\mathrm{~h}$ & 46,05 & cdef & 48,82 & $\mathrm{gh}$ & 17,04 & & 38,16 & $\mathrm{j}$ & 44,95 & \\
\hline Fluodioxonil & 62,89 & c & 50,66 & bcde & 51,32 & fg & 57,77 & $\mathrm{kl}$ & 65,46 & $\mathrm{c}$ & 36,65 & \\
\hline & 5,26 & $\mathrm{~h}$ & 18,68 & $\mathrm{~g}$ & 42,89 & hi & 7,09 & $\mathrm{kl}$ & 21,87 & $\mathrm{i}$ & 42 , & \\
\hline & & $\mathrm{f}$ & 37, & $\mathrm{f}$ & 36 , & $\mathrm{i}$ & 31,53 & $\mathrm{~g}$ & 32 & hi & 36 & \\
\hline Azoxy strobin & 32,89 & fg & 39,87 & ef & 36,32 & $\mathrm{i}$ & 30,62 & $\mathrm{~g}$ & 33,94 & ghi & 31,52 & \\
\hline Pency & 1,05 & hi & 1,58 & $\mathrm{~h}$ & 6,18 & $\mathrm{j}$ & 2,26 & $\mathrm{~m}$ & 4,07 & $\mathrm{j}$ & 8,60 & \\
\hline & 1,32 & hi & $-0,53$ & $\mathrm{~h}$ & $-0,79$ & $\mathrm{j}$ & 3,17 & 1 & 5,28 & $\mathrm{j}$ & 0,45 & \\
\hline C.V. (\%) & 6,62 & & 11,3 & & 6,09 & & 6,16 & & 10,8 & & 3,17 & \\
\hline
\end{tabular}

(1) Média de 5 repetições aos sete dias de incubação.

(2) Médias seguidas pela mesma letra não diferem entre si (Tukey, $\mathrm{p}<0,05$ ).

Os produtos triflumizole, hexaconazole e chlorothalonil variaram de moderadamente eficientes (ED50 $1-10 \mathrm{ppm})$ a pouco eficientes $\left(\mathrm{ED}_{50} 10-50 \mathrm{ppm}\right)$ conforme o isolado de $N$. haematococca. Os fungicidas tiofanato metílico e difenoconazole foram pouco eficientes. Já os fungicidas captan, thiram+vitavax, thiram, procimidone, mancozeb, kresoxim metil, azoxystrobin, pencycuron e oxicloreto de cobre foram considerados ineficientes $\left(\mathrm{ED}_{50}>50 \mathrm{ppm}\right)$ para os dois isolados testados (Tabela 8 e 9). 
Tabela 9. Dose efetiva mediana $\left(E_{50}\right)$ de vários fungicidas relativos à inibição do crescimento micelial de dois isolados de $N$. haematococca, procedentes de Vera Cruz (SP) e Sussuarana (BA) in vitro

\begin{tabular}{lcc}
\hline Tngrediente ativo & $\mathrm{ED}_{50}$ dos fungicidas $(\mathrm{g} / \mathrm{ml})$ & $\mathrm{ED}_{50}$ dos fungicidas $(\mathrm{ig} / \mathrm{ml})$ \\
\cline { 2 - 3 } & Vera Cruz, SP & Sussuarana, BA \\
\hline Prochloraz & $<1$ & $<1$ \\
Thiabendazole & $<1$ & $<1$ \\
Thiram+thiabendole & $<1$ & $<1$ \\
Benomyl & $<1$ & $<1$ \\
Carbendazim & $<1$ & $10-50$ \\
Triflumizole & $1-10$ & $>50$ \\
Captan & $>50$ & $10-50$ \\
Tiofanato metílico & $10-50$ & $>50$ \\
Thiram+vitavax & $>50$ & $1-10$ \\
Hexaconazole & $10-50$ & $10-50$ \\
Difenoconazole & $10-50$ & $<1$ \\
Fluazinam & $<1$ & $>50$ \\
Thiram & $>50$ & $<1$ \\
Iprodione & $<1$ & $1-10$ \\
Chlorothalonil & $>50$ & $>50$ \\
Procimidone & $>50$ & $<1$ \\
Fluodioxonil & $<1$ & $>50$ \\
Mancozeb & $>50$ & $>50$ \\
Kresoxim metil & $>50$ & $>50$ \\
Azoxytrobin & $>50$ & $>50$ \\
Pencycuron & $>50$ & $>50$ \\
Oxicloreto de cobre & $>50$ &
\end{tabular}

Em função dos resultados obtidos in vitro, foram escolhidos os produtos prochloraz, thiabendazole, thiram+thiabendazole, carbendazim, triflumizole e captan para a realização dos experimentos in vivo onde os produtos foram aplicados como erradicante e prochloraz, thiabendazole, carbendazim, triflumizole e difenoconazole para os experimentos in vivo onde o efeito curativo foi testado.

\subsection{Inibição in vitro do crescimento micelial de $P$. parasitica}

Nenhum fungicida inibiu acima de $82 \%$ o crescimento micelial de $P$. parasitica na concentração de 100 ppm de i.a. Os resultados na dose 1 ppm de i.a. foram omitidos em função da baixa eficiência dos fungicidas nessa concentração. Quando empregado 1000 ppm de i.a., dose empregada em condições de campo, os fungicidas kif, 
dimethomorph, metalaxyl+mancozeb, mancozeb, cymoxanil+maneb e oxicloreto de cobre inibiram completamente o crescimento micelial, seguidos por thiram, thiram+thiabendazole, trifenil acetato de estanho, captan e metalaxyl+chlorothalonil. $\mathrm{Na}$ concentração de 100 ppm de i.a. foram eficientes thiram+thiabendazole e trifenil acetato de estanho, seguidos por captan (Tabela 10).

Tabela 10. Porcentagem de inibição do crescimento micelial de $P$. parasitica a diferentes fungicidas e concentrações avaliado em dois experimentos: 1 e 2

\begin{tabular}{|c|c|c|c|c|c|c|c|c|c|c|}
\hline \multirow[t]{2}{*}{ Ingrediente ativo } & Exp. 1 & \multicolumn{2}{|c|}{ Exp. 2} & \multicolumn{2}{|l|}{ Exp. 1} & \multicolumn{2}{|l|}{ Exp. 2} & \multicolumn{2}{|c|}{ Exp. 1} & \multirow{2}{*}{$\begin{array}{l}\text { Exp. } 2 \\
1000 \mathrm{ppm}\end{array}$} \\
\hline & $10 \mathrm{ppm}$ & $10 \mathrm{ppr}$ & & $100 \mathrm{pp}$ & & $100 \mathrm{pp}$ & & $1000 \mathrm{r}$ & $\overline{\mathrm{ppm}}$ & \\
\hline KIF & $58,68 \mathrm{a}$ & 63,23 & & 61,67 & $\mathrm{~d}$ & $67,18 \mathrm{c}$ & & 100,00 & & $100,00^{(\mathrm{t})}$ \\
\hline Dimethomorph & $18,60 \mathrm{a}$ & 64,81 & $a b$ & 56,05 & d & 69,16 & & 100,00 & & 100,00 \\
\hline Metalaxyl+mancozeb & $27,09 \mathrm{~cd}$ & 50,57 & cde & 45,07 & $\mathrm{e}$ & 65,99 & cde & 100,00 & & 100,00 \\
\hline Mancozeb & 25,34 & 46,03 & def & 46,44 & ef & 59,27 & ef & 100,00 & & 100,00 \\
\hline Cymoxanil+maneb & 26,84 & 49,98 & cdef & 42,07 & $\mathrm{f}$ & 58,88 & $\mathrm{f}$ & 100,00 & & 100,00 \\
\hline Oxicloret & 15,23 & $-0,63$ & $\mathrm{i}$ & 19,60 & $\mathrm{~h}$ & 24,08 & $\mathrm{~h}$ & 100,00 & & 100,00 \\
\hline Thiram & 24,97 & 42,47 & $\mathrm{f}$ & 50,94 & $\mathrm{e}$ & 62,83 & def & 99,25 & & $97,63 \mathrm{a}^{(2}$ \\
\hline Thiram+thiabendazole & 33,33 & 43,06 & ef & $79,28 \mathrm{a}$ & & $81,02 \mathrm{a}$ & & 98,00 & & $98,42 \mathrm{a}$ \\
\hline Trifenil acetato estanho & $60,80 \mathrm{a}$ & 65,60 & & 71,41 & & $75,68 \mathrm{a}$ & & 95,63 & & $98,81 \mathrm{a}$ \\
\hline Captan & $24,47 \quad d$ & 19,73 & gh & 68,54 & $\mathrm{c}$ & $70,34 b$ & & 95,63 & & $96,44 \mathrm{a}$ \\
\hline Metalaxyl+chlorothalonil & $41,82 \quad \mathrm{~b}$ & 49,39 & def & 50,06 & $\mathrm{e}$ & 65,01 & cde & 91,14 & $\mathrm{c}$ & $93,87 \mathrm{a}$ \\
\hline Proch & 20,35 de & 16,77 & $\mathrm{~h}$ & 48,94 & $\mathrm{e}$ & 50,77 & $\mathrm{~g}$ & 87,77 & $\mathrm{~d}$ & $87,54 \mathrm{~b}$ \\
\hline Chlor & $56,05 \mathrm{a}$ & 57,69 & $\mathrm{bc}$ & 61,30 & $\mathrm{~d}$ & 66,79 & $\mathrm{~cd}$ & 82,15 & $\mathrm{e}$ & $84,78 \mathrm{~b}$ \\
\hline Flud & $9,61 \mathrm{fg}$ & 2,33 & $\mathrm{i}$ & 16,73 & $\mathrm{~h}$ & 10,24 & $\mathrm{i}$ & 82,15 & $\mathrm{e}$ & $82,60 \mathrm{~b}$ \\
\hline Foset & $15,61 \mathrm{ef}$ & 1,94 & $\mathrm{i}$ & 6,74 & i & 10,64 & $\mathrm{i}$ & 64,17 & $\mathrm{f}$ & $61,64 \mathrm{c}$ \\
\hline Fluazinam & $47,07 \quad \mathrm{~b}$ & 52,16 & $\mathrm{~cd}$ & 48,56 & $\mathrm{e}$ & 51,36 & $\mathrm{~g}$ & 56,30 & $\mathrm{~g}$ & 56,31 \\
\hline Iprodion & 16,60 ef & 2,14 & $\mathrm{i}$ & 25,84 & $\mathrm{~g}$ & 13,20 & $\mathrm{j}$ & 32,58 & $\mathrm{~h}$ & 25,27 \\
\hline Thiabendazo & $1,37 \mathrm{~g}$ & $-0,04$ & $\mathrm{i}$ & 6,12 &. & 9,85 & $\mathrm{ij}$ & 24,22 & $\mathrm{i}$ & 28,43 \\
\hline Kresoxim metil & 21,47 de & 27,24 & $\mathrm{~g}$ & 22,35 & gh & 19,93 & $\mathrm{~h}$ & 24,59 & $\mathrm{i}$ & 25,66 \\
\hline Promocarb & $11,36 \mathrm{f}$ & 3,32 & $\mathrm{i}$ & 16,73 & $\mathrm{~h}$ & 13,01 & $\mathrm{i}$ & 20,10 & $\mathrm{j}$ & 25,66 \\
\hline C.V. (\%) & 9,90 & 7,79 & & 5,55 & & 4,02 & & 1,23 & & 3,15 \\
\hline
\end{tabular}

(1) Média de 5 repetições aos sete dias de incubação.

(2) Médias seguidas pela mesma letra não diferem entre si (Tukey, $\mathrm{p}<0,05$ ).

Considerando a $\mathrm{ED}_{50}$ de todos os fungicidas comparados verifica-se que apenas kif apresentou-se como altamente eficiente $\left(\mathrm{ED}_{50}<1\right)$. Eficiência moderada $\left(\mathrm{ED}_{50} 1-\right.$ 10) foi verificada com trifenil acetato de estanho e chlorothalonil; pouca eficiência $\left(\mathrm{ED}_{50} 10\right.$ - 50) com dimethomorph, thiram+thiabendazole e metalaxyl+chlorothalonil. 
Os outros fungicidas estudados apresentaramse ineficientes $\left(\mathrm{ED}_{50}>50 \mathrm{ppm}\right)$ na inibição do crescimento micelial in vitro (Tabela 11).

Tabela 11. Dose efetiva mediana $\left(\mathrm{ED}_{50}\right)$ de vários fungicidas quanto a inibição do crescimento micelial de P. parasitica sob condições in vitro

\begin{tabular}{lc}
\hline Ingrediente ativo & $\mathrm{ED}_{50}$ dos fungicidas (ì $\left./ \mathrm{ml}\right)$ \\
\hline KIF & $<1^{*}$ \\
Metalaxyl+mancozeb & $>50$ \\
Mancozeb & $>50$ \\
Cymoxanil+maneb & $1-50$ \\
Dimethomorph & $>50$ \\
Oxicloreto de cobre & $1-50$ \\
Thiram+thiabendazole & $1-10$ \\
Trifenil acetato de estanho & $>50$ \\
Captan & $1-10$ \\
Chlorothalonil & $>50$ \\
Thiram & $1-50$ \\
Metalaxyl+chlorothalonil & $>50$ \\
Prochloraz & $>50$ \\
Fluazinam & $>50$ \\
Iprodione & $>50$ \\
Kresoxim metil & $>50$ \\
Fludioxonil & $>50$ \\
Promocarb & $>50$ \\
Fosetyl-Al & $>50$ \\
Thiabendazole & \\
\hline
\end{tabular}

* Valores correspondentes à média de dois experimentos com cinco placas cada.

Em função dos resultados obtidos in vitro, foram escolhidos os produtos kif, dimethomorph, metalaxyl+mancozeb, mancozeb, cymoxanil+chlorothalonil e oxicloreto de cobre para a realização dos experimentos in vivo onde os produtos foram aplicados como erradicantes em solo infestado e kif, dimethomorph, metalaxyl+mancozeb, cymoxanil+chlorothalonil e fosetyl-Al para os experimentos in vivo onde o efeito curativo foi testado. 


\subsection{Tratamento químico erradicante em solo infestado}

Os fungicidas empregados como erradicantes (Tabela 2) em solo infestado com $N$. haematococca e P. parasitica controlaram a doença com ausência de lesões no colo das plantas. Das cinco plantas inoculadas com $N$. haematococca e não submetidas ao tratamento químico, nenhuma havia morrido quatro meses após a inoculação, porém quatro plantas desenvolveram lesões no colo com média de $1,5 \mathrm{~cm}$ de comprimento. Já $P$. parasitica causou a morte de três plantas e um comprimento médio de lesão de 1,2 $\mathrm{cm}$ nas duas plantas sobreviventes. O fungicida thiabendazole apresentou fitotoxidez na dosagem utilizada (300 g p.c./100L) expressa por necrose foliar, desfolha e morte de duas plantas, sendo o desenvolvimento das três sobreviventes severamente afetado.

Sintomas de damping-off foram observados nos solos infestados com $P$. parasitica não submetidos aos fungicidas, com uma média de 2,6 plantas tombadas por saco. Algumas plântulas morreram nos tratamentos com difenoconazole, dimethomorph, triflumizole e solo não infestado com os patógenos, provavelmente em decorrência da falta de água uma vez que não foram observados lesões nas raízes e colo das plântulas.

\subsection{Tratamento químico curativo}

Os cinco fungicidas sistêmicos testados, dentre estes prochloraz com ação em profundidade, apresentaram inibição do desenvolvimento da doença, quando comparados à testemunha inoculada com $N$. haematococca que apresentou duas mortes. Os fungicidas prochloraz e carbendazim destacaram-se em evitar a morte das plantas enquanto triflumizole e difenoconazole apresentaram uma planta morta. O fungicida thiabendazole apresentou fitotoxidez expressa pela morte de três plantas e com o desenvolvimento das duas sobreviventes severamente afetado. $\mathrm{O}$ desenvolvimento da lesão no colo das plantas foi menor qua ndo os fungicidas foram aplicados dois dias após a inoculação do patógeno comparado aos sete dias após a inoculação (Tabela 12). As plantas não inoculadas com os patógenos apresentaram um comprimento médio de lesão cicatrizada de $0,5 \mathrm{~cm}$, decorrente do ferimento com o furador de três milímetros de diâmetro (dados não apresentados). 
Tabela 12. Comprimento $(\mathrm{cm})$ de lesões ou morte da planta (+) após inoculação de Nectria haematococca quando submetidas ou não ao tratamento com fungicidas, dois ou sete dias após a inoculação

\begin{tabular}{cccccccccccc}
\hline $\begin{array}{l}P . \text { edulis f. } \\
\text { flavicarpa }\end{array}$ & $\begin{array}{c}\text { testem. } \\
\text { inocul. }\end{array}$ & \multicolumn{9}{c}{$\begin{array}{c}\text { thiabenda- } \\
\text { zole }\end{array}$} & \multicolumn{2}{c}{ carbendazim } & \multicolumn{2}{c}{ triflumizole } & \multicolumn{2}{c}{$\begin{array}{c}\text { difenoco- } \\
\text { nazole }\end{array}$} \\
& & $2 \mathrm{~d}$ & $7 \mathrm{~d}$ & $2 \mathrm{~d}$ & $7 \mathrm{~d}$ & $2 \mathrm{~d}$ & $7 \mathrm{~d}$ & $2 \mathrm{~d}$ & $7 \mathrm{~d}$ & $2 \mathrm{~d}$ & $7 \mathrm{~d}$ \\
\hline $1^{(1)}$ & + & 1,2 & 1,8 & $+^{(2)}$ & 1,6 & 1,6 & 1,9 & 1,4 & + & + & 2,3 \\
2 & + & 0,9 & 1,5 & $+^{(2)}$ & 0,9 & 1,1 & 1,6 & 1,0 & 1,3 & 1,4 & 1,8 \\
3 & 2,1 & 0,9 & 0,9 & $+^{(2)}$ & 0,9 & 1,1 & 1,2 & 1,0 & 1,1 & 1,4 & 1,4 \\
4 & 1,6 & 0,8 & 0,8 & 0,8 & 0,6 & 0,7 & 1,0 & 0,9 & 1,0 & 1,0 & 1,1 \\
5 & 0,7 & 0,6 & 0,6 & 0,6 & 0,6 & 0,7 & 0,9 & 0,8 & 1,8 & 0,8 & 0,9 \\
\hline
\end{tabular}

(1) Repetição = planta de P. edulis f. flavicarpa .

${ }^{(2)}$ Morte causada por fitotoxidez.

Os cinco fungicidas empregados no controle de $P$. parasitica reduziram a doença, comparados à testemunha inoculada não submetida aos fungicidas. Os produtos kif, metalaxyl+mancozeb, dimethomorph e cymoxanil+maneb apresentaram eficiência semelhante e superior quando aplicados dois dias após a inoculação, comparado a sete dias quando algumas plantas já evidenciavam cancros no colo acima do solo. Fosetyl-Al foi inferior aos demais fungicidas, com comprimentos de lesões maiores e morte de duas plantas quando aplicado aos dois e sete dias após a inoculação, respectivamente (Tabela 13).

Tabela 13. Comprimento $(\mathrm{cm})$ de lesões ou morte de maracujazeiro (+) após inoculação de Phytophthora parasitica quando submetidas ou não ao tratamento com fungicidas, dois ou sete dias após a inoculação

\begin{tabular}{|c|c|c|c|c|c|c|c|c|c|c|c|}
\hline \multirow[t]{2}{*}{$\begin{array}{l}\text { P. edulis f. } \\
\text { flavicarpa }\end{array}$} & \multirow[t]{2}{*}{$\begin{array}{l}\text { testem. } \\
\text { inocul. }\end{array}$} & \multicolumn{2}{|c|}{ kif } & \multicolumn{2}{|c|}{$\begin{array}{l}\text { metalaxyl + } \\
\text { mancozeb }\end{array}$} & \multicolumn{2}{|c|}{$\begin{array}{c}\text { cymoxanil + } \\
\text { maneb }\end{array}$} & \multicolumn{2}{|c|}{$\begin{array}{l}\text { dimetho- } \\
\text { morph }\end{array}$} & \multicolumn{2}{|c|}{ fosetyl-AI } \\
\hline & & $2 \mathrm{~d}$ & $7 \mathrm{~d}$ & $2 d$ & $7 \mathrm{~d}$ & $2 \mathrm{~d}$ & $7 \mathrm{~d}$ & $2 \mathrm{~d}$ & $7 \mathrm{~d}$ & $2 \mathrm{~d}$ & $7 \mathrm{~d}$ \\
\hline $1^{(1)}$ & + & 2,0 & + & + & 3,2 & 2,0 & + & 1,6 & + & 3,7 & + \\
\hline 2 & + & 1,9 & 2,4 & 1,8 & 2,2 & 1,9 & 2,4 & 1,6 & 2,8 & 2,8 & + \\
\hline 3 & + & 1,6 & 1,9 & 1,8 & 1,9 & 1,6 & 2,1 & 1,5 & 2,4 & 2,5 & 3,1 \\
\hline 4 & 3,2 & 1,4 & 1,9 & 1,4 & 1,7 & 1,3 & 2,0 & 1,3 & 2,0 & 1,9 & 2,8 \\
\hline 5 & 1,6 & 1,0 & 1,2 & 0,8 & 1,6 & 1,1 & 1,1 & 1,3 & 1,5 & 1,8 & 1,7 \\
\hline
\end{tabular}

${ }^{(1)}$ Repetição = planta de P. edulis f. flavicarpa.

(2) Morte causada por fitotoxidez. 


\section{DISCUSSÃO}

Os sintomas observados nas plantas de maracujazeiro inoculadas com $N$. haematococca e $P$. parasitica foram murcha acompanhada de amarelecimento foliar, seguida de seca e morte das plantas, resultado do completo anelamento do colo ao nível do solo e apodrecimento das raízes.

A confirmação da patogenicidade dos isolados obtidos a partir de plantas doentes evidenciou a importância de N. haematococca no Estado de São Paulo, levando a acreditar que o mesmo seja o responsável pelo caráter itinerante da cultura a partir da década de 70 no Estado. Embora $P$. parasitica tenha sido constatado apenas uma vez em nossos isolamentos, o mesmo já foi constatado causando a doença em maracujazeiros procedentes de Marília (SP) (Palmira R. Righeto Rolim, comunicação pessoal).

Os resultados obtidos nas provas de patogenicidade e metodologias de inoculação coincidem com as apreciações de Emechebe \& Mukiibi (1976), Lin \& Chang (1985), Cedeño et al. (1990) e Lutchemech \& Musaphur (1993) de que N. haematococca é um patógem que causa doença unicamente na presença de ferimentos. Emechebe \& Mukiibi (1976) sugeriram que o processo infeccioso é favorecido pelas lesões provocadas pela emergência das raízes laterais, implementos agrícolas, insetos do solo e nematóides. O patógeno $P$. parasitica, ao contrário de $N$. haematococca, mostrou-se capaz de infectar diretamente os tecidos de plântulas como também observado por Cole et al. (1992) e Gonzalez et al. (2000), embora a suscetibilidade diminua com a idade das plântulas.

Em condições naturais de campo a morte prematura é observada principalmente em plantas adultas, porém sob condições favoráveis, como o plantio em solos com histórico da doença e elevada temperatura e umidade no solo, as plantas novas podem 
sucumbir ao ataque dos patógenos, poucos meses após terem sido transplantadas (Melo, 1990; Ponte et al., 1998). Experimentalmente, inoculações artificiais com $N$. haematococca e $P$. parasitica, através de ferimentos, evidenciaram maior suscetibilidade das plantas novas, expressa em nú mero de plantas mortas e comprimento de lesões, em função do menor diâmetro no córtex do colo e do sistema radicular (Emechebe \& Mukiibi, 1976; Cole et al., 1992).

A escolha do método de inoculação por deposição de disco de micélio no colo previamente ferido e idade das plantas de seis semanas pós-germinação nos experimentos de avaliação de comportamento de Passifloraceas e genótipos de P. edulis f. flavicarpa foi em função da eficácia na reprodução dos sintomas da doença e por permitir quantificar a doença através do desenvolvimento ascendente e descendente das lesões no colo das plantas de P. edulis f. flavicarpa. Plantas novas, com três semanas pós-germinação, mostraram-se altamente suscetíveis, não permitindo identificar prováveis fontes de resistência, enquanto que plantas de nove semanas foram pouco afetadas pelos patógenos, nas condições experimentais adotadas. A eficiência das inoculações na reprodução dos sintomas da doença quando a massa micelial e a suspensão de esporos foram depositadas no colo das plantas também foi verificada por Emechebe \& Mukiibi (1976), Lin \& Chang (1985), Cedeño et al. (1990), Delanoë (1991), Ploetz (1991) e Cole et al. (1992).

Inoculações no sistema radicular, embora experimentalmente menos eficientes na reprodução dos sintomas da doença foram importantes na avaliação do comportamento de Passifloraceas e devem ser adotadas em adição às inoculações na região do colo.

Os maiores índices de damping-off quando os patógenos estavam associados podem ser explicados pela porta de entrada provocada por $P$. parasitica à infecção de $N$. haematococca. Segundo Cole et al. (1992), a dessecação dos tecidos infectados indicou que apenas $N$. haematococca efetivamente colonizou o tecido, porém na presença de $P$. parasitica a extensão do tecido invadido foi maior.

A escolha da época de inoculação dos patógenos, priorizando as mais quentes, mostrouse um fator importante no desenvolvimento da doença, como já observado por 
Turner (1974) e Matta (1984), e que deve ser levada em consideração em futuros experimentos.

O maracujá-amarelo variedade Sul-Brasil apresentou elevada suscetibilidade a $N$. haematococca e P. parasitica comparado às outras Passifloraceas. Em curto prazo, a utilização de porta-enxertos resistentes parece ser o mais indicado em áreas infestadas. No entanto, plantas enxertadas são menos produtivas, mais fracas e apresentam menor capacidade de recuperação após desfolha por outras doenças.

Algumas espécies como P. edulis, P. alata, P. giberti, P. caerulea, P. quadrangularis e $P$. macrocarpa mostraram-se passíveis de utilização como portaenxertos para o maracujazeiro amarelo, embora diferentes níveis de compatibilidade tenham sido observados (Manica, 1981; Menezes, 1990). Yamashiro \& Landgraff (1979) indicaram P. alata como um promissor porta-enxerto, pois além de ser resistente ao patóge no causador da "murcha", confere à copa maior precocidade e não apresenta alteração na qualidade dos frutos, permitindo também o uso de solos mais úmidos (favoráveis ao patógeno). $P$. caerulea é amplamente usado como porta-enxerto de $P$. edulis f. edulis na África do Sul onde é resistente a $F$. oxyporum f.sp. passiflorae, $P$. parasitica e Meloidogyne spp. (Ssekyewa et al., 1999). P. nitida apresenta potencial tanto para produção de frutos como para utilização em programas de melhoramento genético de $P$. edulis f. flavicarpa, pela alta rusticidade em relação à resistência a pragas e doenças dos maracujazeiros além de alto vigor vegetativo e produtivo, porém soluções para os problemas de dormência das sementes desta espécie devem ser buscadas (Menezes, 1990).

A alta variabilidade genética de $P$. edulis f. flavicarpa perceptível pelas diferenças na suscetibilidade aos patógenos condiz ao observado nos outros trabalhos. Delanoë (1991) classificou a espécie como altamente suscetível a $N$. haematococca, Ssekyewa et al. (1999) a considerou parcialmente resistente, enquanto Lin \& Chang (1985) encontrou algumas linhagens resistentes ao patógeno. Resultados promissores de resistência do maracujazeiro amarelo a $P$. parasitica já foram encontrados por Milne et al. (1975), Brodrick et al. (1976) e Lin \& Chang (1985), indicando a possibilidade do 
melhoramento genético intraespecífico ser mais promissor, considerando aspectos favoráveis de compatibilidade e produtividade da espécie.

A variabilidade observada entre e dentro de espécies do gênero Passiflora para resistência a doenças e pragas tem sido estudada e caracterizada com o objetivo de aproveitá-la nos programas de melhoramento e utilização de porta-enxertos. Cunha \& Cardoso (1998) relatam os trabalhos desenvolvidos na FCAV/UNESP (Jaboticabal, SP), buscando transferir genes de resistência à morte prematura de $P$. alata para $P$. edulis $\mathrm{f}$. flavicarpa, na Empresa Pernambucana de Pesquisa Agropecuária (IPA, PE) onde estão sendo pesquisadas fontes de resistência a Fusarium e virose para o desenvolvimento de cultivares intra e interespecíficos e para uso como porta-enxertos e também na Universidade Estadual da Bahia (Vitória da Conquista, BA) onde o comportamento de oito espécies de Passiflora está sendo avaliado com relação à morte prematura visando identificar porta-enxertos para maracujá-amarelo resistentes a esta enfermidade.

Por ser uma planta alógama, vários são os métodos de melhoramento aplicáveis ao maracujazeiro, como o aumento da frequiência dos genes favoráveis ou a exploração do vigor híbrido ou heterose. A freqüência de genes favoráveis pode ser aumentada pela seleção massal, como as populações conhecidas por "Maguary" e "Sul-Brasil" ou pela seleção com teste de progênies (Bruckner et al., 2002) e o vigor híbrido explorado por meio de híbridos, variedades sintéticas ou composto, como os obtidos por Meletti (1998) e Meletti et al. (2000).

$\mathrm{O}$ emprego de fungicidas para o controle emergencial da morte prematura em áreas infestadas pode ser uma ferramenta importante, considerando que as variedades utilizadas são suscetíveis. Resultados promissores foram aqui obtidos com os fungicidas selecionados in vitro em tratamento erradicante em solo infestado, inibindo o processo infeccioso para ambos os patógenos e reduzindo o desenvolvimento da doença através do emprego de fungicidas sistêmicos, em tratamento curativo. Resultados satisfatórios de controle de $N$. haematococca foram encontrados em condições naturais de campo por Ponte et al. (1998) e Ssekyewa et al. (1999) com o tratamento das covas com PCNB e rega do colo com oxicloreto de cobre, respectivamente. Resultados de controle insatisfatório eventualmente poderão ocorrer em condições favoráveis à ocorrência da 
doença como o transplantio em solo infestado em épocas de elevada temperatura e umidade, como observado por Melo et al. (1990) para o patógeno $P$. parasitica. Estudos mais detalhados em condições naturais de campo se fazem necessários para avaliar a eficácia dos fungicidas, épocas e intervalos de aplicação, dose, fitotoxidez, etc., e assim estabelecer as melhores alternativas de controle químico para o agricultor. Fungicidas sem registros para a cultura podem ser fitotóxicos como observado com o produto thiabendazole. Atenção do agricultor aos sintomas iniciais da doença no pomar aumenta as chances de sucesso do controle químico curativo pois um melhor índice de controle é obtido com a doença em seu estágio inicial. Em regiões com histórico da doença um controle químico preventivo poderá ser indicado nas condições predisponentes à doença como após práticas culturais que ocasionem ferimentos ao colo e sistema radicular (transplante, coroamento) e durante as estações quentes e úmidas.

Para o controle de ervas daninhas deve-se dar preferência ao emprego de herbicidas ou roçadera como forma de se evitar ferimentos nas raízes. Especificamente no Estado de São Paulo, onde a doença é predominantemente provocada por $N$. haematococca, a prevenção de ferimentos é por si só uma importante medida de controle que pode minimizar a ocorrência da doença. 


\section{CONCLUSÕES}

Com base nos resultados obtidos pode-se concluir:

- N. haematococca destaca-se como o principal agente da morte prematura do maracujazeiro no Estado de São Paulo;

- A prática de ferimentos na região do colo ou no sistema radicular das plantas favorece a ocorrência da doença;

- Temperaturas elevadas favorecem a infecção de $N$. haematococca e P. parasitica;

- Maior suscetibilidade é verificada em plantas de P. edulis f. flavicarpa mais novas e com os patógenos em associação;

- O maracujazeiro variedade Sul-Brasil é mais suscetível aos patógenos que a maioria das espécies de Passiflora;

- Há alta variabilidade quanto a suscetibilidade das diferentes Passifloraceas e genótipos de P. edulis f. flavicarpa, evidenciando a possibilidade de sucesso no controle da morte prematura com o uso e porta-enxertos resistentes e com o desenvolvimento de híbridos/variedades de maracujazeiro amarelo resistentes em programas de melhoramento;

- O controle químico pode ser utilizado emergencialmente tanto em tratamento erradicante em solo infestado, quanto em tratamento curativo, reduzindo o número de plantas mortas ou o comprimento das lesões para ambos os patógenos. 


\section{REFERÊNCIAS BIBLIOGRÁFICAS}

AGUIAR, D.R.D.; SANTOS, C.C.F. Importância econômica e mercado. In: BRUCKNER, C.H.; PIÇANVO, M.C.; MANICA, I. (Ed.). Maracujá: tecnologia de produção, pós-colheita, agroindústria, mercado. Porto Alegre: Cinco Continentes, 2001. 472p.

BOLLEN, .J.; FUCKS, A. On the specificity of the in vitro and in vivo antifungal activity of benomyl. Netherland Journal of Plant Pathology, v.76, p.299-313, 1970.

BOOTH, C. Fusarium: Laboratory guide to identification of the major species. Kew, Surrey: Commonweath Mycological Institute, 1977. 17p.

BRODRICK, H.T.; MILNE, D.L; WOOD, R.; MULDER, N.J. Control of Phytophthora steam-rot of granadillas in south Africa. The Citrus and Subtropical Fruit Journal, n.508, p.15-17, 1976.

BRUCKNER, C.H.; MELETTI, L.M.N.; OTONI, W.C..; ZERBINI JUNIOR, F.M. Maracujazeiro. In: BRUCKNER, C.H. (Ed.). Melhoramento de fruteiras tropicais. Viçosa: UFV, 2002. 422p.

CACEX/Carteira de Comércio Exterior do Banco do Brasil. Notícias. Revista Informação Semanal, n.22, p.23-24, 1987.

CEDEÑO, L.; PALACIOS-PRU, E.; MARQUES, N.J.; TAVIRA, M.E. Nectria haematococca, agente causal de la muerte repentina de la parchita em Venezuela. Fitopatología Venezolana, v.3, n.1, p.15-18, 1990.

COHEN, Y.; COFFEY, M.D. Systemic fungicides and control of oomycetes. Annual Review Phytopathology, v.24, p.311-338, 1986. 
COLE, D.L.; HEDGES, R.; NDOWORA, T. A wilt of passion fruit (Passiflora edulis f. edulis Sims) caused by Fusarium solani and Phytophthora nicotianae var. parasitica. Tropical Pest Management, v.38, n.4, p.362-366, 1992.

CUNHA, M.A.P.; CARDOSO, C.E.L. Variabilidade genética e melhoramento do maracujá. In: QUEIRÓS, M.A. de; GOEDERT, C,O; RAMOS, S.R.R. (Ed.). Recursos genéticos e melhoramento de plantas para o nordeste brasileiro. Petrolina: Embrapa Semi-Árido; Brasília: Embrapa Recursos Genéticos e Biotecnologia, nov. 1998. http://www.cpatsa.embrapa.br (15 jan. 2003).

DELANOË, O. Etude de la résistance de passiflores de Guyane française vis-à-vis de Fusarium pathogènes de la culture des fruits de la Passion (Passiflora edulis $\mathrm{f}$. flavicarpa). Fruits, v.46, n.5, p.593-600, 1991.

EDGINGTON, L.V.; KHEN, K.L.; BARRON, G.L. Fungitoxic spectrum of benzimidazole compounds. Phytopathology, v.61, p.42-44, 1971.

EMBRAPA CERRADOS - Empresa Brasileira de Pesquisa Agropecuária Cerrados. Diversos relatórios e site (www.cpac.embrapa.br/fruteiras.htm)

EMECHEBE, A.M.; MUKIIBI, J. Nectria collar and root rot of passion fruit in Uganda. Plant Disease Reporter, v.60, n.3, p.227-231, 1976.

FISCHER, I. H.; KIMATI, H.; HAMAGUSHI, W. Ocorrência de Fusarium solani e Phytophthora parasitica, causando morte prematura do maracujazeiro em Vera Cruz, SP. Summa Phytopathologica, v.29, p.54, 2003 a.

FISCHER, I. H.; MARTINS, M. C.; LOURENCO, S. A.; KIMATI, H.; AMORIM, L. Reação de espécies de Passiflora à podridão do colo, causada por Fusarium solani e Phytophthora parasitica. Fitopatologia Brasileira, v.28, p.271, 2003 b.

FNP CONSULTORIA \& AGROINFORMATIVOS. Agrianual 2003: anuário estatístico da agricultura brasileira. São Paulo, 2003, p.399-405: maracujá.

FREITAS, P.C.D. Possibilidades farmacológicas. In: RUGGIERO, C. (Ed.). Maracujá. Ribeirão Preto: Legis Summa, 1987, p.210-217.

GARDNER, D.E. Pathogenicity of Fusarium oxysporum f.sp. passiflorae to banana poka and other Passiflora spp. in Hawaii. Plant Disease, v.73, n.6, p.476-478, 1989. 
GONZALEZ, M.S.; SUAREZ, Z.; ROSALES, C. Collar rot and wilt of yellow passion fruit in Venezuela. Plant Disease, v.84, n.1, p.103, 2000.

GRECH, N.M.; RIJKENBERG, F.H.J. Laboratory and field evaluation of the performance of Passiflora caerulea as a rootstock tolerant to certain fungal root pathogens. Journal of Horticultural Science, v.66, n.6, p.725-729, 1991.

HO, H.H. Synoptic keys to the species of Phytophthora. Mycologia, v.73, p.705-714, 1981.

KATARIA, H.R.; GROVER, R.K. Comparison of fungicides for the control of Rhizoctonia solani causing damping-off of mung bean (Phaseolus aureusi). Annual Applied Biology, v.88, p.257-263, 1978.

KUEH, T.K.; VOON, B.H. Phytophthora wilt of passion fruit. In.: ANNUAL REPORT OF THE RESEARCH BRANCH, DEPARTAMENT OF AGRICULTURE, SARAWAK, FOR THE YEAR 1983. Kuching, Sarawak, Minist. Agric. Community Development, 1985. 115 p. [In: Review of Plant Pathology, v.66, n.3, p.116, 1987. (Abst. 1082)].

LI, D.F.; YANG, J.Q.; ZHANG, X.Y.; SUN, L.F. Identification of the pathogen causing collar rot of passion fruit in Fujian. Acta Phytopathologica Sinica, v.23, n.4, p.372, 1993. [In Review of Plant Pathology, v.73, n.9, p.722, 1994. (Abst. 5876)].

LIN, Y.S.; CHANG, H.J. Collar rot of passion fruit possibly caused by Nectria haematococca in Taiwan. In: PARKER, C.A.; ROVIRA, A.D.; MOORE, K.J.; ONG, P.T.W.; KOLLMORGEN, J.F. (Ed). Ecology and management of soilborne plant pathogens . St. Paul: APS Press, 1985. p.41-45.

LUTCHMEAH, R.S.; MUSAPHUR, F.B. Sudden wilt of yellow passion fruit (Passiflora edulis f. flavicarpa) caused by Fusarium solani in Mauritius. FAO Plant Protection Bulletin, v.41, n.2, 1993.

MANICA, I. Fruticultura Tropical, maracujá. São Paulo: Agronômica Ceres, 1981. $160 \mathrm{p}$.

MARTIN, F.W.; NAKASONE, H.Y. The edible species of Passiflora. Economic Botany, v.24, n.3, p.333-343, 1970. 
MASUDA, Y. Doenças fúngicas do maracujazeiro. In: SIMPÓSIO SOBRE A CUlTURA DO MARACUJÁ, 3., Campinas, 1974. Anais. Campinas: CATI, 1974. p.1-10.

MATTA, E.A.F. Doenças do maracujazeiro no Estado da Bahia. Salvador: EPABA, 1982. 17p. (Circular Técnica, 2).

McKNIGHT, T. A wilt of the passion vine (Passiflora edulis) caused by a species of Fusarium. The Queensland Journal of Agricultural Science, v.8, n.1, p.1-4, 1951.

MELETTI, L.M.M., Caracterização agronômica de progênies de maracujá-amarelo (Passilora edulis Sims. f. flavicarpa Deg.). Piracicaba, 1998. 92p. Tese (Doutorado) - Escola Superior de Agricultura “Luiz de Queiroz”, Universidade de São Paulo.

MELETTI, L.M.M.; SANTOS, R.R.; MINAMI, K. Melhoramento do maracujazeiro amarelo: obtenção do cultivar “composto IAC-27”. Scientia Agrícola, v.57, n.3, p.491-498, 2000.

MELO, M.B.; BATISTA, F.A.S.; SILV A, L.M.S.; TRINDADE, J. Controle da podridão de raízes do maracujazeiro Passiflora edulis f. flavicarpa Deg. Revista Brasileira de Fruticultura, v.12, p.7-12, 1990.

MENEZES, J.M.T. Seleção de porta-enxertos tolerantes a morte prematura de plantas para Passiflora edulis Sims f. flavicarpa Deg. e comportamento de Passiflora nitida HBK na região de Jaboticabal. Jaboticabal, 1990. 73p. Dissertação (Mestrado) Faculdade de Ciência Agrárias e Veterinárias - Campus de Jaboticabal, Universidade Estadual Paulista.

MILNE, D.L., KUHNE, F.A.; BRODRICK, H.T.; LOGIE, J.M.; DEVILLIERS, E.A.; WOOD, R. Yellow granadilla outshines purple granadilla in yield and disease resistance. The Citrus and Sub Tropical Fruit Journal, n.502, p.11-12, 1975.

MITCHELL， D.J; KANNWISCHER-MITCHELL, M.E. Phytophthora. In: SINGLETON, L.L., MIHAIL, J.D; RUSH, C.M. Methods for Research on Soilborne Phytopathogenic Fungi. St. Paul, Minnesota: APS Press, 1992. cap.2, p.31-38.

NAKAMURA, K. Murcha e morte do maracujazeiro. In: RUGGIERO. C. (Ed.). Cultura do maracujazeiro . Jaboticabal: FCAV, 1980. p.103-104. 
NUNES A.M.L.; ALBUQUERQUE, F.C. Podridão do coleto do maracujazeiro (Passiflora edulis). Fitopatologia Brasileira, v.20, p.356, 1995.

OLIVEIRA, J.C. Melhoramento genético. In: RUGGIERO, C. (Ed.). Maracujá. Ribeirão Preto: Legis Summa, 1987. p.218-246.

OLIVEIRA, G.H.N.; SUDO, S.; SILVA, J.R.; AKIBA, F. Fusarium solani envolvido na morte precoce do maracujazeiro Passiflora edulis f. flavicarpa. Fitopatologia Brasileira, v.13, n.2, p.142, 1988.

OLIVEIRA, J.C.; RUGGIERO, C. Aspectos sobre o melhoramento do maracujazeiro amarelo. In: SIMPÓSIO BRASILEIRO SOBRE A CULTURA DO MARACUJÁ, 5., Jaboticabal, 1998. Anais. Jaboticabal SP: FUNEP, 1998. p.291-310.

PEREIRA, M.C.; OLIVEIRA, J.C.; NACHTIGAL, J.C. Propa gação vegetativa do maracujá-suspiro (Passiflora nitida) por meio de estacas herbáceas. In: SIMPÓSIO BRASILEIRO SOBRE A CULTURA DO MARACUJÁ, 5., Jaboticabal, 1998. Anais. Jaboticabal SP : FUNEP, 1998. p.317.

PIZA JUNIOR, C.T. Moléstias fúngicas do maracujazeiro. In: SÃO JOSÉ, A. R. (Ed.). Maracujá: produção e mercado. Vitória da Conquista: DFZ./UESB, 1994. p.108115 .

PIZA JUNIOR, C.T. A cultura do maracujá na região sudeste do Brasil. In: SIMPÓSIO BRASILEIRO SOBRE A CULTURA DO MARACUJÁ, 5., Jaboticabal, 1998. Anais. Jaboticabal: FUNEP, 1998. p.20-48.

PLOETZ, R.C. Sudden wilt of passionfruit in southern Florida caused by Nectria haematococca. Plant Disease, v.75, n.10, p.1071-1073, 1991.

PONTE , J.J. da. As doenças do maracujá-amarelo no nordeste do Brasil. Revista Brasileira de Fruticultura, v.15, p.11-14, 1993.

PONTE, J.J. da., FRANCO, A.; AGUIÁR DE HOLANDA, Y.C.; SILVEIRA FILHO, J. Calagem, adubação orgânica e fungicida de solo no controle da podridão do pé (Fusarium solani) do maracujá-amarelo. Fitopatología Venezolana, v.12, n.2, p.30-31, 1998. 
PURSS, G.S. Studies of the resistance of species of Passiflora to Fusarium wilt ( $F$. oxysporum f. passiflorae). Queensland Journal of Agricultural Science, n.15, p.95-99, 1954.

RAZERA PAPA, R.C. Morte prematura. Toda Fruta, Julho/90, p.19-21.

RUGGIERO, C.; OLIVEIRA, J.C. Enxertia do maracujazeiro. In: SIMPÓSIO BRASILEIRO SOBRE A CULTURA DO MARACUJÁ, 5., Jaboticabal, 1998. Anais. Jaboticabal: FUNEP, 1998. p.70-92.

RUGGIERO, C., SÃO JOSÉ, A.C. VOLPE, J. DE OLIVEIRA, J. DURIGAN, J. BAUNGARTNER, J. DA SILVA, K. NAKAMURA, M. FERREIRA, R. KAVATI, Y V. PEREIRA. Maracujá para exportação: aspectos técnicos da produção. Brasília: FRUPEX-EMBRAPA, 1996.63p.

SANTOS FILHO, H.P. Murchas do maracujazeiro. Cruz das Almas: EmbrapaCNPMF. 1993. 2p. (Maracujá em Foco, 73).

SIMMONDS, J.H. Science branch Plant Pathology Section. Report of Departament of Agriculture, Queensland, 1959. p.49-50.

SOUZA, J.S.I; MELETTI, L.M.M. Maracujá: espécies, variedades e cultivo. Piracicaba: FEALQ, 1997. 179p.

SSEKYEWA, C.; FINA OPIO, A.; SWINBURNE, T.R.; VAN DAMME, P.L.V.; ABUBAKAR, Z.M. Sustainable management of collar rot disease of passion fruits in Uganda. International Journal of Pest Management, v.45, n.3, p.173-177, 1999.

TERBLANCHE, J.H.; BRECH, N.; FREAN, R.; CRABÉE, F.; JOUBERT, A. Good news for passion fruit industry. Citrus and Subtropical Fruit Research Institute Information Bulletin, n.164, p.1-5, 1987.

TURNER, G.J. Phytophthora wilt and crown rot of Passiflora edulis. Transactions of the British Mycological Society, v.62, n.1, p.59-63, 1974.

VAN DEN BOOM, T.; HULLER, I.M. Phytophthora stem rot of passion fruit (Passiflora edulis) in south Africa. Phytophylactica, v.2, p.71-74, 1970.

VANDERPLANK, J. Passion flowers. London: Cambridge Press, 1996. 224p. 
VIENNOT-BORGIN, G. Les champignons parasites des plantes cultivées. Paris: Masson, 1949. 1849p.

YAMASHIRO, T.; PALAZZO, D.A.; GRISI JUNIOR., C. Doenças do maracujazeiro constatadas no Estado de São Paulo. In: CONGRESSO BRASILEIRO DE FRUTICULTURA, 2., Viçosa, 1973. Anais. Viçosa, MG: Sociedade Brasileira de Fruticultura, 1973, v.2, p.411-419.

YAMASHIRO, T.; LANDGRAFF, J.H. Maracujá-açu (Passiflora alata Ait), portaenxerto resistente à fusariose do maracujazeiro (Passiflora edulis f. flavicarpa Deg.). In: CONGRESSO BRASILEIRO DE FRUTICULTURA, 5., Pelotas, 1979. Anais. Pelotas, RS: Sociedade Brasileira de Fruticultura, 1979. p.918-921.

YOUNG, B.R. Root rot of passion fruit vine (Passiflora edulis Sims) in the Auckland area. New Zealand Journal of Agriculture Research, n.13, p.119-125, 1970. 